\title{
Detection and Activity Profiling of Synthetic Cannabinoids and Their Metabolites with a Newly Developed Bioassay
}

\author{
Annelies Cannaert, ${ }^{\dagger}$ Jolien Storme, $^{\dagger}$ Florian Franz, $^{\dagger}$ Volker Auwärter, ${ }^{\ddagger}$ and Christophe P. Stove ${ }^{* \dagger}$ \\ ${ }^{\dagger}$ Laboratory of Toxicology, Department of Bioanalysis, Faculty of Pharmaceutical Sciences, Ghent University, Ottergemsesteenweg \\ 460, 9000 Ghent, Belgium \\ ${ }^{\ddagger}$ Institute of Forensic Medicine, Forensic Toxicology, Medical Center - University of Freiburg, Faculty of Medicine, University of \\ Freiburg, Albertstr. 9, 79104 Freiburg, Germany
}

\section{Supporting Information}

ABSTRACT: Synthetic cannabinoids (SCs) are the largest group of compounds currently monitored in Europe by the EU Early Warning System on new psychoactive substances. Emerging recreational use of these products has led to multiple cases of adverse health effects and even death. In contrast to marijuana, where $\Delta^{9}$-tetrahydrocannabinol $\left(\Delta^{9} \mathrm{THC}\right)$ is metabolized to only one major active metabolite, it has been reported that several major phase I metabolites of SCs remain biologically active, exerting cannabinoid (CB) receptor affinity, potency, and efficacy greater than those of $\Delta^{9}$ THC. It is therefore reasonable that more SCs can also be biotransformed into molecules with various levels of $\mathrm{CB}$

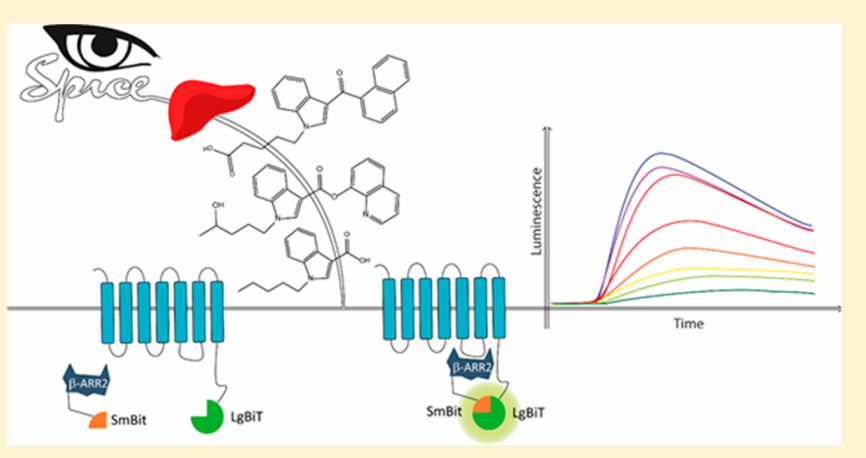
activity. Here, we developed and applied a new G-protein coupled receptor (GPCR) activation assay based on NanoLuc binary technology (Promega). More specifically, by demonstrating CB1 and CB2 receptor activation by JWH-018 and a selection of its metabolites, we are the first to show the suitability of the newly developed bioassay for monitoring GPCR-mediated activity. We also successfully applied this reporter system to evaluate the in vitro activity of JWH-122, JWH-210, and PB-22, their 5-fluoro analogues (MAM-2201, EAM-2201, and 5F-PB-22, respectively), and their main phase I metabolites. By doing so, we demonstrate that several major metabolites of these SCs retain their activity at cannabinoid receptors. All of these active metabolites may prolong the parent compound's psychotropic and physiological effects and may contribute to its toxicity profile. We also demonstrate a proof of concept of the applicability of the newly developed bioassay for screening urine for CB receptor activity exerted by SCs.

S ynthetic cannabinoid $(\mathrm{CB})$ receptor agonists, commonly referred to as synthetic cannabinoids (SCs), are the largest group of compounds currently monitored in Europe by the EU Early Warning System on new psychoactive substances (NPS). ${ }^{1}$ Although they are marketed as a "safe" and "legal" alternative to marijuana, recent reports indicate that many of these compounds may produce serious adverse health effects. ${ }^{2,3}$ SCs were originally synthesized by research laboratories to investigate the endocannabinoid system or as potential therapeutic drugs because they interact with cannabinoid receptors $\mathrm{CB} 1$ and $\mathrm{CB} 2$. Currently, however, they have reappeared through the Internet as designer drugs, so-called "legal highs". ${ }^{4-6}$ In contrast to the major psychoactive constituent of marijuana, $\Delta^{9}$-tetrahydrocannabinol ( $\left.\Delta^{9} \mathrm{THC}\right)$, which is a partial agonist at both receptors, SCs may act as full agonists and may be selective for one receptor subtype. ${ }^{7}$ The psychoactive effects derive from agonistic activity at $\mathrm{CB} 1$, predominantly found in the central nervous system. CB2 receptors are mainly associated with the immune system, but they are also expressed at a lower density in the brain..$^{8-10} \mathrm{CB} 1$ and $\mathrm{CB} 2$ are G-protein coupled receptors (GPCRs). They are coupled through the Gi/o family of G-proteins to signal transduction mechanisms that include inhibition of adenylyl cyclase, activation of mitogen-activated protein kinase, regulation of calcium and potassium channels (CB1 only), and other signal transduction pathways. GPCRs are rapidly desensitized by recruitment of the cytosolic protein $\beta$-arrestin 2 ( $\beta$ arr2). ${ }^{11}$

Unlike the widespread use of marijuana, which poses only relatively limited acute toxicity, serious adverse effects, often requiring medical attention, are not uncommon with SC consumption. Indeed, the relative risk of seeking emergency medical treatment following the use of SCs has been reported to be 30 times higher than that associated with the use of natural forms of cannabis. ${ }^{12}$ Observed effects include central effects (psychosis, paranoia, agitation, seizures, and anxiety), cardiotoxic effects, acute kidney failure, respiratory depression, rhabdomyolysis, withdrawal symptoms, coma, and even

Received: July 8, 2016

Accepted: October 25, 2016

Published: October 25, 2016 
death. ${ }^{4,7,13,14}$ The reason for the more profound adverse effects is not fully clear. It is known that the majority of SCs exhibits a higher affinity, potency, and efficacy at both the CB1 and CB2 receptors compared to those of $\Delta^{9} \mathrm{THC}$. As $\mathrm{SC}$ products may be a combination of several compounds, it is possible that the resulting activation of $\mathrm{CB} 1$ and/or $\mathrm{CB} 2$ produces stronger physiological and psychotropic effects. Another difference between $\Delta^{9} \mathrm{THC}$ and SCs is their metabolism. In contrast to marijuana, where $\Delta^{9}$ THC is metabolized to only one major active metabolite, ${ }^{15}$ it has been reported that several major metabolites of JWH-018, JWH-073, AM-2201, UR-144, and XLR-11 are still biologically active, exerting greater CB1 affinity, potency, and efficacy than $\Delta^{9} \mathrm{THC}$, both in vitro and in vivo. ${ }^{16-19}$ The metabolites of JWH-018 and JWH-073 also maintain their in vitro activity at $\mathrm{CB} 2{ }^{20}$ It is therefore reasonable to assume that other SCs are also biotransformed into molecules with various levels of activity at the $\mathrm{CB}$ receptors. These active metabolites may prolong the parent compound's psychotropic and physiological effects and may contribute to its toxicity profile. Greater knowledge of the activity of relevant metabolites of a wider set of SCs may allow us to gain better insight into the contribution of these active metabolites to the toxicity observed with SCs. Although there may be differences between in vitro and in vivo activities, these seem to be correlated; therefore, in vitro assays may serve this purpose.

Current methods used in the literature to determine the in vitro activity of SCs (and their metabolites) are the $\left.{ }^{35} \mathrm{~S}\right] \mathrm{GTP} \gamma \mathrm{S}$ binding assay, ${ }^{17-26}$ a quantitative internalization assay, ${ }^{27,28}$ adenylyl cyclase assays, ${ }^{20,29,30}$ and the commercial FLIPR membrane potential assay from Molecular Devices. ${ }^{16,30,31}$ There are also commercially available $\beta$-arrestin recruitment assays, which have been evaluated for CB1 and CB2 cannabinoid receptors. These include the imaging-based Redistribution and Transfluor assays (from Thermo Fisher Scientific and Molecular Devices, respectively) and the nonimaging-based Tango and PathHunter assays (from Thermo Fisher Scientific and DiscoveRx, respectively). ${ }^{32,33}$

The GTP $\gamma$ S binding assay directly measures the guanine nucleotide exchange of G-proteins, an early event after GPCR activation. Although this assay could be applied (because $\mathrm{CB}$ receptors are $\mathrm{Gi} /$ o-coupled), the radioactivity, high background, and requirement for a filtration step are important drawbacks. ${ }^{34-36}$ The quantitative internalization assay, which evaluates the remaining percentage of cell surface receptors via antibody staining as a measurement of receptor activation, is not preferred as it is labor-intensive due to the multiple washing and binding steps. Adenylyl cyclase assays are based on the quantification of second messenger cAMP. However, in the case of $\mathrm{Gi} / \mathrm{o}$-coupled receptors, prestimulation is required (e.g., with forskolin, a direct activator of the adenylyl cyclase). ${ }^{35,36}$ The FLIPR membrane potential assay is designed to measure intracellular changes in calcium levels by using calcium-sensitive fluorescent dyes. The rapid and transient calcium flux makes the assay unsuitable for detecting slow binding agonists. Also, the use of a fluorescent readout may lead to false positive signals due to possible interference from other compounds. ${ }^{35,36}$ The Redistribution and Transfluor assays evaluate receptor activation by monitoring receptor internalization via fusion proteins with green fluorescent protein (GFP). While a benefit of these assays is the real-time measurement and visualization of the GFP fusion protein during the internalization process, they require a dedicated imaging system and offer a relatively low throughput. In the Tango assay, GPCR activation is evaluated by the release of a transcription factor, which leads to expression of a reporter protein that can be quantified. Although reporter gene assays are sensitive, there are some concerns. These include the need for long incubation times, difficulties in antagonist detection due to reporter accumulation, and the high potential for false positives as reporter protein expression is a distal event to receptor activation. In the PathHunter assay, the $\beta$-arrestin-receptor interaction is measured via enzyme fragment complementation of $\beta$ galactosidase. The PathHunter assay, just as the Tango assay, can be read on a standard multimode reader and is easily adaptable for high-throughput screening, but its advantage over the Tango assay is that the detection is proximal to the receptor. The downsides of the PathHunter assay are its lack of flexibility for the end user and the limited time window for detection as the $\beta$-arrestin-receptor interaction is measured only 90-120 min after stimulation with the test compound. $33,35-37$

Here, we developed and applied a new GPCR activation assay based on NanoLuc binary technology (Promega). This technology has already successfully been applied to study protein-protein interactions. ${ }^{38}$ We report on the application of this assay for the monitoring of GPCR activation, via ligandinduced interaction of $\beta$ arr2 with a given GPCR. More specifically, by demonstrating activation of $\mathrm{CB} 1$ and $\mathrm{CB} 2$ cannabinoid receptors by JWH-018 and a selection of its metabolites, we are the first to show the suitability of the newly developed bioassay for activity profiling of GPCR ligands. Next, we applied this reporter system to evaluate the in vitro activity of JWH-122, JWH-210, and PB-22, their 5-fluoro analogues (MAM-2201, EAM-2201, and 5F-PB-22, respectively), and their main phase I metabolites (Figure 1). By doing so, we demonstrate that several major metabolites of these SCs retain their activity at $\mathrm{CB}$ receptors. We also demonstrate a proof of concept of the applicability of the newly developed bioassay for detecting the presence of $\mathrm{CB}$ receptor activating compounds, notably SCs (and their metabolites), in urine.

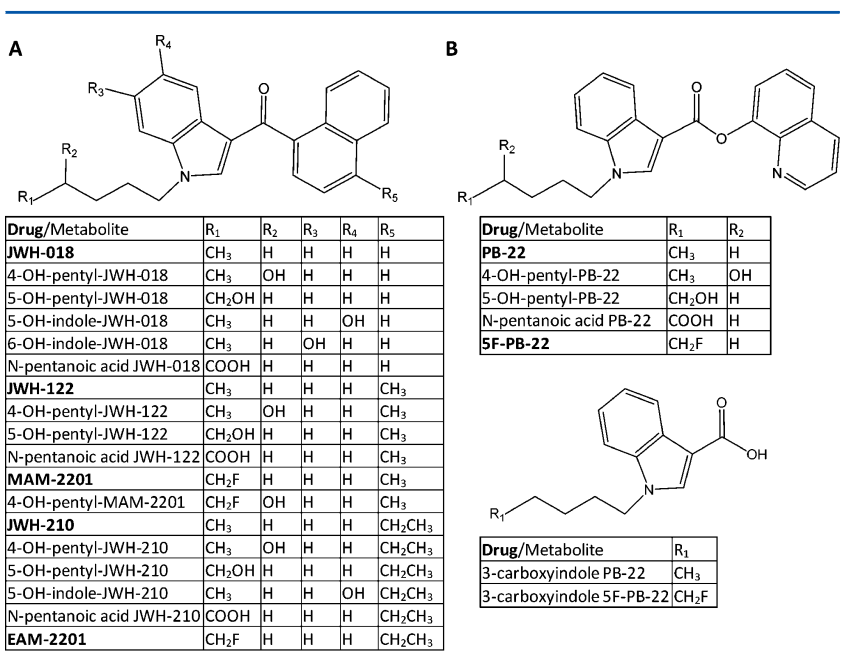

Figure 1. Structures of SCs and metabolites. (A) SCs belonging to the aminoalkylindole family: JWH-018, JWH-122, MAM-2201, JWH-210, and EAM-2201. (B) PB-22 and 5F-PB-22, belonging to the indolecarboxylate family. 


\section{MATERIALS AND METHODS}

Chemicals and Reagents, Plasmids and Constructs, and Cell Culture and Transfection. Chemicals and reagents were obtained as described in the Supporting Information (Data S1). Expression vectors encoding human $\mathrm{CB} 1$ or $\mathrm{CB} 2$ receptor or $\beta$-arrestin 2, fused via a flexible linker to the subunits of NanoLuc luciferase ( $\mathrm{LgBiT}$ or $\mathrm{SmBiT}$ ), were generated using standard molecular biology techniques, as outlined in Supporting Information Data S1. These constructs were used to transiently transfect human embryonic kidney (HEK) $293 \mathrm{~T}$ cells, which were seeded in poly-D-lysine-coated 96-well plates at $5 \times 10^{4}$ cells/well and incubated overnight before performing the assay. More details can be found in Supporting Information Data S1.

Cannabinoid Reporter Assay. Forty-eight hours after transfection, the cells were washed twice with Opti-MEM I reduced serum medium to remove any remaining FBS, and 100 $\mu \mathrm{L}$ of Opti-MEM I was added. The Nano-Glo Live Cell reagent, a nonlytic detection reagent containing the cellpermeable furimazine substrate, was prepared by diluting the Nano-Glo Live Cell substrate 20× using Nano-Glo LCS Dilution buffer, and $25 \mu \mathrm{L}$ was added to each well. Subsequently, the plate was placed in a GloMAX96 (Promega). Luminescence was monitored during the equilibration period until the signal was stabilized $(30-45 \mathrm{~min})$. For agonist experiments, we added $10 \mu \mathrm{L}$ per well of test compounds, present as $13.5 \times$ stocks in $50 \%$ methanol in Opti-MEM I. Luminescence was continuously detected for $120 \mathrm{~min}$. For antagonist experiments, $5 \mu \mathrm{L}$ of the antagonist stock solution (26X stock solution in 50\% methanol in Opti-MEM I) was incubated for $5 \mathrm{~min}$ before adding $5 \mu \mathrm{L}$ of agonist $(27 \times$ stock solution in 50\% methanol in Opti-MEM I). The luminescence was continuously detected for $120 \mathrm{~min}$. Solvent controls were run in all experiments; the final concentration of methanol (3.7\%) did not pose a problem given the advantage of the short readout time of the assay.

Statistical Analysis. Curve fitting and statistical analyses were performed using GraphPad Prism software (San Diego, CA, USA). To select the optimal configuration for the CB reporter assay for both $\mathrm{CB}$ receptors, results are represented as mean area under the curve (AUC) \pm standard error of mean (SEM) with six replicates for each data point (unless stated otherwise) and were statistically analyzed using Student's $t$ test after F-test and Grubbs' outliers test $(\alpha=0.05)$. Curve fitting of concentration-effect curves via nonlinear regression was employed to determine $\mathrm{EC} / \mathrm{IC}_{50}$ (a measure of potency). To evaluate the activity of the different SCs and their metabolites, results are represented as the percentage (\%) $\mathrm{CB}$ activation (relative to the receptor activation of JWH-018) \pm SEM, with at least three replicates for each data point. Here, the absolute signals were baseline-corrected by subtracting the vehicle control samples and were corrected for the interwell variability before the AUC calculations (see Supporting Information Data S2). A one-way ANOVA, followed by Dunnett's post hoc test, was used to determine statistical significance $(P<0.05)$ (i) between all compounds and the reference compound JWH018, (ii) within a group between a parent compound and the other compounds in that group (e.g., all compounds related to JWH-122 vs JWH-122), and (iii) between the signals obtained from the compounds and those from solvent controls. To plot the activity profiles of the natural cannabinoids and urinary samples, the normalized raw data are shown (see Supporting Information Data S2).

Urine Sample Preparation. For conjugate cleavage, 0.5 $\mathrm{mL}$ of phosphate buffer, $\mathrm{pH} 6$, and $30 \mu \mathrm{L}$ of $\beta$-glucuronidase were added to $0.5 \mathrm{~mL}$ of urine, followed by a $1 \mathrm{~h}$ incubation at $45{ }^{\circ} \mathrm{C}$. Then, $1.5 \mathrm{~mL}$ of ice-cold acetonitrile and $0.5 \mathrm{~mL}$ of 10 $\mathrm{M}$ ammonium formate were added. The mixture was shaken and centrifuged. One milliliter of the organic phase was transferred to a separate vial and evaporated to dryness under a stream of nitrogen. For analysis with the applied CB reporter assay, the evaporated extract was reconstituted in $100 \mu \mathrm{L}$ of Opti-MEM I/MeOH (50/50, v/v), of which $10 \mu \mathrm{L}$ was used per well (see the Cannabinoid Reporter Assay section). For LC-MS/MS analysis, another $0.5 \mathrm{~mL}$ aliquot was spiked with internal standards $(2 \mathrm{ng} / \mathrm{mL}$; see Supporting Information Data S3) and processed as described above. The residue was reconstituted in $200 \mu \mathrm{L}$ of mobile phase $\mathrm{A} / \mathrm{B}(50 / 50, \mathrm{v} / \mathrm{v})$ prior to LC-MS/MS analysis.

LC-ESI-MS/MS Analysis of Urine Samples. Quantification of SC metabolites in a genuine urine sample was performed by applying a semiquantitative LC-MS/MS method. Selectivity and specificity were tested by analyzing six blank samples. Linearity was given for all analytes from 0.01 to 10.0 $\mathrm{ng} / \mathrm{mL}$. The lowest calibrator level was defined as the lower limit of quantification (LLOQ). Precision $(<15 \%)$ and accuracy $(< \pm 15 \%)$ were assessed by analysis of control samples. Concentrations below the calibration range were extrapolated using the peak area ratio of the lowest calibrator and were reported only if the identification criteria were fulfilled (retention time, signal-to-noise ratio > 3:1, qualifier ion/ quantifier ion ratio). Matrix effects were not assessed since semiquantitative values were considered acceptable for the proof-of-concept comparison with the qualitative results of the applied reporter assay. Settings used for the chromatographic separation and the tandem mass spectrometry analysis are described elsewhere. ${ }^{39}$ For details on the optimized MS settings of the quantified analytes and internal standards, see Supporting Information Data S3.

\section{RESULTS AND DISCUSSION}

Design of the CB Reporter Assay. NanoLuc binary technology utilizes a structural complementation-based approach to monitor protein interactions within living cells. It makes use of inactive subunits of NanoLuc luciferase, Large BiT (LgBiT; $18 \mathrm{kDa})$ and Small BiT (SmBiT; $1 \mathrm{kDa})$, which are coupled to two proteins of interest. Protein interaction promotes structural complementation of the subunits, thereby restoring NanoLuc luciferase activity, which generates a bioluminescent signal in the presence of the furimazine substrate. To monitor GPCR activation, we made use of its stimulation-dependent interaction with the cytosolic adaptor protein $\beta$ arr2, which mediates receptor desensitization and internalization in a widely distributed manner throughout the GPCR family. ${ }^{40-42}$ Here, we aimed at establishing assays capable of monitoring activation of $\mathrm{CB} 1$ and $\mathrm{CB} 2$ receptors using a panel of SCs and their metabolites. To this end, we designed constructs in which the $\mathrm{LgBiT}$ or SmBiT subunit is coupled to the $\mathrm{CB} 1$ or $\mathrm{CB} 2 \mathrm{C}$-terminus and to the $\mathrm{N}$ - or $\mathrm{C}$ terminus of $\beta$ arr2. To assess the functional complementation of the $\mathrm{LgBiT}$ and $\mathrm{SmBiT}$ fusion proteins upon GPCR activation, all possible combinations were tested by stimulation with a known agonist, JWH-018 (Figure 2). 


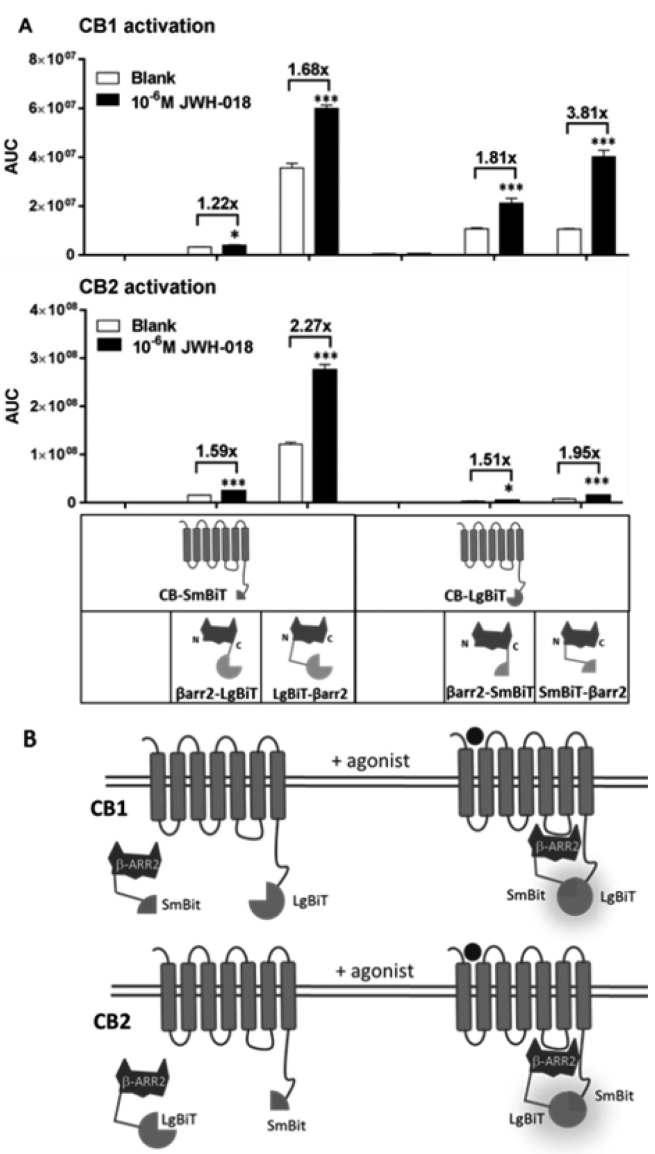

Figure 2. Comparison of the different combinations at both $\mathrm{CB}$ receptors. (A) $\mathrm{CB}$ reporter assays for $\mathrm{CB} 1$ (upper graph) and $\mathrm{CB} 2$ (lower graph). A stimulation-dependent interaction of $\beta$ arr2 with both $\mathrm{CB}$ receptors was consistently observed. No ligand-dependent effects could be detected for the single $\mathrm{CB}$ fusion protein. Data are given as the mean AUC $\pm \operatorname{SEM}(n=5-6) ; * P \leq 0.01, * * P \leq 0.001, * * * P \leq$ 0.0001 (two-sided $t$-test). (B) Optimal design of the $\mathrm{CB}$ reporter assays for $\mathrm{CB} 1$ and $\mathrm{CB} 2$ : $\mathrm{CB} 1-\mathrm{LgBiT} / \mathrm{SmBiT}-\beta$ arr2 and $\mathrm{CB} 2-$ SmBiT/LgBiT- $\beta$ arr2.

Whenever both the $\mathrm{CB}$ and $\beta$ arr2 fusion proteins were present together, unstimulated cells readily showed a signal above background (i.e., the signal when only the CB fusion protein was present), pointing at some level of constitutive $\mathrm{CB}-\beta$ arr2 interaction (open bars in Figure 2A). Regardless of the combination of $\mathrm{CB}$ and $\beta$ arr2 fusion proteins used, a significant increase in signal was observed upon agonist stimulation (closed bars in Figure 2A). The highest signals were observed for the $\mathrm{CB}-\mathrm{SmBiT} / \mathrm{LgBiT}-\beta$ arr2 combinations. For $\mathrm{CB} 2$, this combination also yielded the largest increase (2.27-fold) when comparing stimulated vs nonstimulated cells. For CB1, however, the combination of $\mathrm{CB} 1-\mathrm{LgBiT} / \mathrm{SmBiT}-\beta$ arr2, although it gave somewhat lower absolute signals, yielded the largest increase (3.81-fold) following activation. Hence, further experiments were performed with cells that were transiently transfected with either the $\mathrm{CB} 1-\mathrm{LgBiT} / \mathrm{SmBiT}-\beta$ arr2 combination or the $\mathrm{CB} 2-$ $\mathrm{SmBiT} / \mathrm{LgBiT}-\beta$ arr2 combination (Figure $2 \mathrm{~B}$ ).

Concentration Dependence of the CB Reporter Assays. Upon stimulation with a known agonist, JWH-018, CB1-LgBiT and CB2-SmBiT showed a concentrationdependent interaction with $\mathrm{SmBiT}-\beta$ arr2 and $\mathrm{LgBiT}-\beta$ arr2, respectively, with $\mathrm{EC}_{50}$ values of 38.2 and $12.8 \mathrm{nM}$ (Table 1
Table 1. $\mathrm{EC}_{50}$ Values of Different SCs ${ }^{a}$

\begin{tabular}{lcc}
\multicolumn{1}{c}{ drug } & $\mathrm{CB}_{1 \mathrm{EC}_{50}(\mathrm{nM})}$ & $\mathrm{CB}^{2} \mathrm{EC}_{50}(\mathrm{nM})$ \\
JWH-018 & $38.2(27.1-55.7)$ & $12.8(5.6-26.0)$ \\
JWH-122 & $71.7(52.3-104.4)$ & $9.2(5.1-15.9)$ \\
MAM-2201 & $60.5(44.3-87.5)$ & $2.7(1.1-5.1)$ \\
JWH-210 & $25.3(18.3-34.7)$ & $17.5(10.1-29.1)$ \\
EAM-2201 & $4.8(3.2-7.2)$ & $3.7(1.9-6.5)$ \\
PB-22 & $0.86(0.53-1.33)$ & $0.82(0.30-1.46)$ \\
5F-PB-22 & $0.84(0.51-1.40)$ & $0.70(0.47-0.97)$
\end{tabular}

${ }^{a} \mathrm{EC}_{50}$ values are presented as a measure of potency. Data are given as $\mathrm{EC}_{50}$ values (95\% CI profile likelihood).

and Figure 3A,B). Also, for other synthetic cannabinoids, concentration-dependence was obtained and $\mathrm{EC}_{50}$ values were determined as a measure of relative potency (Table 1; graphs are shown in Supporting Information Data S4). Although it is difficult to compare $\mathrm{EC}_{50}$ values from different assays (due to different experimental setups), our values are in line with those found in the literature. More specifically, reported $\mathrm{EC}_{50}$ values for CB1 of JWH-018, JWH-122, and JWH-210 ([ $\left.{ }^{35} \mathrm{~S}\right] \mathrm{GTP} \gamma \mathrm{S}$ binding assay: $36,32.9$, and $20.4 \mathrm{nM}$, respectively) ${ }^{24}$ are in line with the $\mathrm{EC}_{50}$ values we obtained, ranging from 25.3 to 71.7 $\mathrm{nM}$ (Table 1). For PB-22 and 5F-PB-22, which are known to have an even higher potency, ${ }^{16}$ we obtained subnanomolar $\mathrm{EC}_{50}$ values using the newly developed assay. Again, these $\mathrm{EC}_{50}$ values match the order of magnitude of those found in the literature (FLIPR membrane potential assay: CB1 5.1 and 2.8 $\mathrm{nM}$ vs $102 \mathrm{nM}$ for JWH-018; CB2 37 and $11 \mathrm{nM}$ vs $133 \mathrm{nM}$ for JWH-018). ${ }^{16}$ Our data are also in line with the observation by Banister et al. that terminal fluorination of the N-pentyl results in increased $\mathrm{CB}$ receptor potency. ${ }^{16}$ For $\mathrm{CB} 1$, the parent compounds JWH-122, JWH-210, and PB-22 and their 5-fluoro analogues (MAM-2201, EAM-2201 and 5F-PB-22, respectively) showed CB1 activation that was significantly higher than the reference JWH-018 (graphs are shown in Supporting Information Data S4). This may point at an intrinsic high efficacy of these compounds or, alternatively, to more efficient recruitment of $\beta$ arr 2 upon receptor activation, or both. The JWH-018-induced recruitment of $\beta$ arr2 to CB1 was blocked by Rimonabant, a selective CB1 antagonist, in a concentrationdependent manner (Figure 3C), demonstrating the specificity of the assay. Curve fitting of concentration-effect curves via nonlinear regression was employed to determine the $\mathrm{IC}_{50}$ of Rimonabant, which was $11.4 \mathrm{nM}$ (95\% CI profile likelihood: 8.6-15.1 nM) and is in line with the $\mathrm{IC}_{50}$ value of $17.6 \mathrm{nM}$ (Eu-GTP $\gamma \mathrm{S}$ binding assay) found in the literature. ${ }^{43}$

Application of the CB Reporter Assays on SCs and Their Main Phase I Metabolites. JWH-018. JWH-018 was the first SC reported in Germany in December 2008 as one of the active components of the herbal blend "Spice"., ${ }^{5,6}$ it is a naphthoylindole, belonging to the aminoalkylindole family. Although its chemical structure differs substantially from that of $\Delta^{9} \mathrm{THC}$, it produces similar effects and has been reported to be more potent than $\Delta^{9} \mathrm{THC}$ (data shown in Supporting Information Data S5). Importantly, several metabolites of JWH-018 have been reported to have partial to full agonist activity at CB1 and CB2. ${ }^{18-20}$ To further validate our newly developed CB reporter assay, we applied it to JWH-018 and a selection of its metabolites, reported as the major phase I metabolites occurring in urine, i.e., the 4- and 5-OH-pentyl, 5and 6-OH-indole, and the N-pentanoic acid metabolites. ${ }^{44-46}$ 


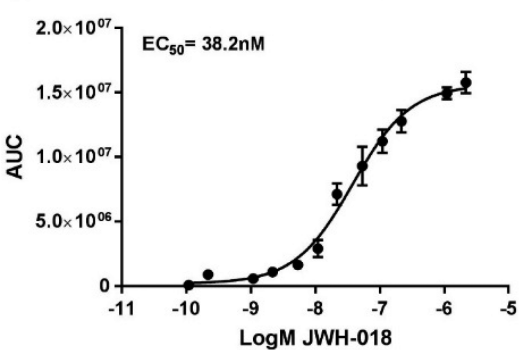

B

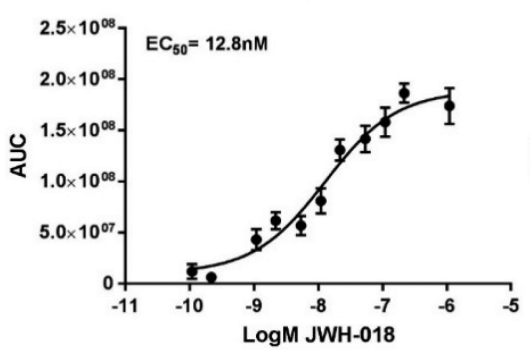

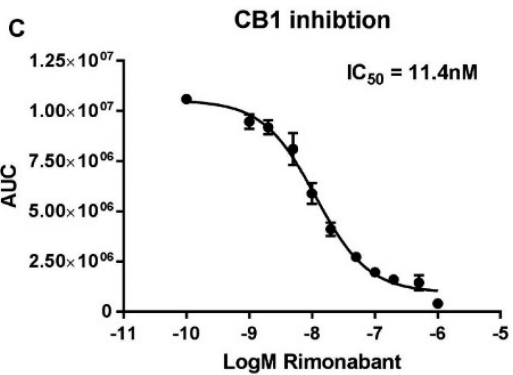

Figure 3. Concentration-dependent interaction of CB1 (A) and CB2 (B) with $\beta$ arr2 upon stimulation with JWH-018. (C) Interaction of $\beta$ arr2 with the $\mathrm{CB} 1$ receptor, induced by $\mathrm{JWH}-018$ at its $\mathrm{ED}_{80}$ concentration, was blocked by Rimonabant, a selective $\mathrm{CB} 1$ antagonist, in a concentrationdependent manner. AUC, area under the curve (luminescence over time). Data are given as the mean AUC \pm SEM $(n=5-6)$.

For each of these compounds, we assessed $\beta$ arr2 recruitment to either the CB1 or CB2 receptor at an arbitrarily chosen concentration of $1 \mu \mathrm{M}$, corresponding to a receptor saturating concentration of JWH-018. Unlike JWH-018 and all of the monohydroxylated metabolites, which activated both $\mathrm{CB}$ receptors (Figure 4, Supporting Information Data S6), the N-
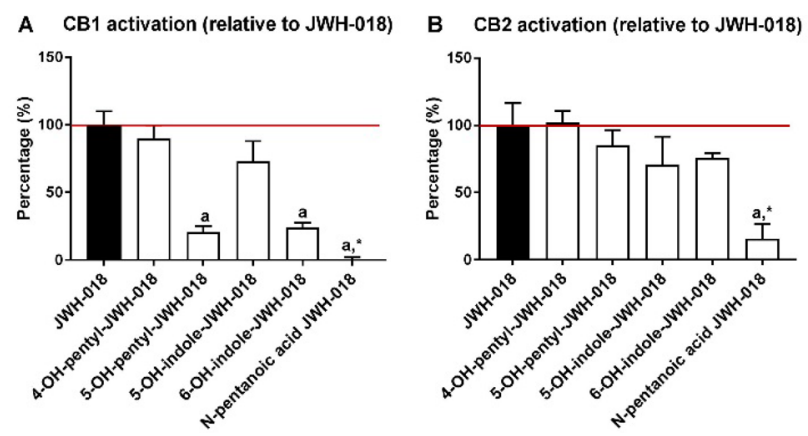

Figure 4. Activation of $\mathrm{CB} 1$ receptor $(\mathrm{A})$ and $\mathrm{CB} 2$ receptor (B) by JWH-018 and its major phase I metabolites at $1 \mu \mathrm{M}$. Bars assigned with (a) above the error bars are significantly different from the reference compound JWH-018 ( $P \leq 0.05$, one-way ANOVA with Dunnett's multiple comparison post hoc test). Bars assigned with an (*) are not significantly different from basal levels. Data are given as mean \% CB receptor activation (in comparison to the receptor activation of the reference, JWH-018) $\pm \operatorname{SEM}(n=$ at least 3 replicates).

pentanoic acid metabolite did not induce a significant difference from basal levels at both receptors, which is in line with its reported lack of affinity for $\mathrm{CB} 1$ and $\mathrm{CB} 2$ receptors $\left(K_{\mathrm{i}}\right.$ for $\mathrm{CB} 1$ and $\mathrm{CB} 2 \geq 10000 \mathrm{nM}){ }^{18,20}$

The extent of $\mathrm{CB} 1$ and $\mathrm{CB} 2$ activation varied for individual metabolites. For CB1, there was no statistical difference in the level of receptor activation by the 4-OH-pentyl and 5-OHindole metabolites when compared to the JWH-018 parent compound. The two other hydroxylated metabolites $(5-\mathrm{OH}-$ pentyl and 6-OH-indole metabolites) produced significantly less CB1 activation, 20.7 and $24.1 \%$ relative to JWH-018, respectively (Figure 4A and Supporting Information Data S6). For CB2, all hydroxylated metabolites yielded a signal that was not significantly different from that obtained after stimulation with $\mathrm{JWH}-018$, indicating that these metabolites also retain their activity at CB2 (Figure 4B), which is consistent with the literature. ${ }^{18-20}$ It is worth noting that, when compared to the literature, there is no perfect overlay in the relative activity of the metabolites. Several reasons may account for these more subtle differences, most notably the different experimental setups that have been used (e.g., $\left[{ }^{35} \mathrm{~S}\right] \mathrm{GTP} \gamma \mathrm{S}$ binding assay and adenylyl cyclase assay vs $\beta$ arr2 recruitment). ${ }^{18-20}$

JWH-122, JWH-210, MAM-2201, and EAM-2201. JWH-122 and JWH-210 and their 5-fluoro analogues, MAM-2201 and EAM-2201, respectively, belong to the naphthoylindole family. They only differ from JWH-018 by the addition of a methyl/ ethyl on the naphthyl moiety (Figure 1). These SCs became popular in 2010-2011 after the prohibition of the "first generation" of SCs (e.g., JWH-018, JWH-073). ${ }^{47,48}$ The shift to these agonists, some of which are more potent than JWH-018 (Table 1), has led to more cases with serious symptoms, including a reported fatality of MAM-2201 poisoning. ${ }^{49-52}$ Biotransformation of JWH-122 and MAM-2201 leads to common metabolites: the 5-OH-pentyl and N-pentanoic acid JWH-122 metabolites. MAM-2201 also produces trace amounts of the 4-OH-pentyl-MAM-2201 metabolite. ${ }^{53}$ Both in vitro metabolism studies ${ }^{53}$ and analyses of authentic urine samples from users (unpublished observations) ${ }^{53}$ demonstrated that the 5-OH-pentyl-JWH-122 metabolite was the primary phase I metabolite of MAM-2201, whereas the 4-OH-pentyl-JWH-122 metabolite was predominant and exclusive in JWH-122 metabolism. ${ }^{53}$ From the available reference standards for metabolites of JWH-210, the 4-OH-pentyl metabolite was the most prevalent phase I metabolite in urine. The other phase I metabolites that were present in decreasing abundance are the 5-OH-indole and 5-OH-pentyl metabolites. For EAM-2201, the 5-OH-pentyl-JWH-210 metabolite was the most abundant phase I metabolite in the urine of users, followed by the Npentanoic acid JWH-210 metabolite (unpublished observations). Since the activity of these metabolites at $\mathrm{CB}$ receptors is not known, we evaluated these with our new bioassay. Again, all compounds were tested at $1 \mu \mathrm{M}$, with JWH-018 as a reference.

JWH-122, MAM-2201, JWH-210, EAM-2201, and all of the monohydroxylated metabolites showed significant activation of both receptors. The N-pentanoic acid JWH-122 metabolite did not induce a significant difference from basal levels at both receptors, but, unexpectedly, the N-pentanoic acid JWH-210 metabolite did show $\mathrm{CB} 2$ receptor activation, which, although somewhat lower, was not significantly different from the parent compound, JWH-210. (Figure 5A,B and Supporting Information Data S6). The signal obtained for almost all hydroxylated metabolites was not significantly different from that induced by the corresponding parent compounds, JWH-122 and JWH-210. Only 5-OH-pentyl-JWH-122 and 5-OH-indole-JWH-210 yielded signals that were significantly lower, but they still induced levels of $\mathrm{CB} 1$ activation that were not statistically different from our reference compound, JWH-018. For CB2, there was no statistical difference in the level of receptor 
A

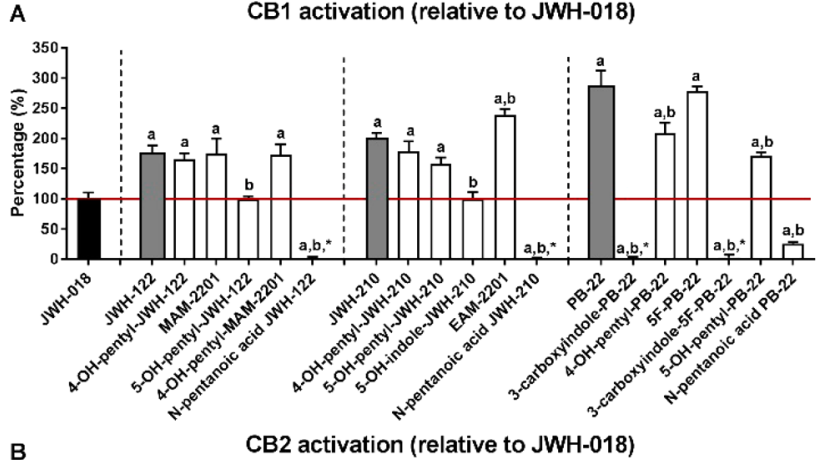

B

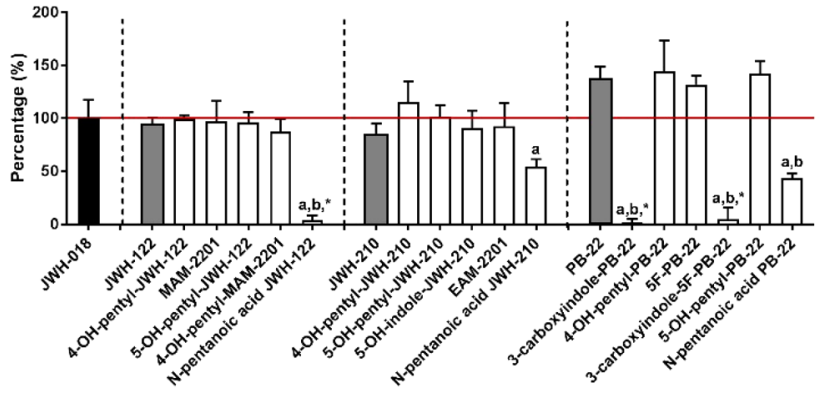

Figure 5. Activation of $\mathrm{CB} 1$ receptor (A) and $\mathrm{CB} 2$ receptor (B). Values designated with (a) above error bars denote a significant difference from the reference compound, JWH-018 ( $P \leq 0.05$, oneway ANOVA with Dunnett's multiple comparison post hoc test). Values designated with (b) are significantly different from the reference compound within a group (groups are separated via vertical dotted lines). Bars assigned with an $(*)$ are not significantly different from basal levels. Data are given as the mean percentage CB receptor activation (in comparison to the receptor activation of the reference, $\mathrm{JWH}-018) \pm \operatorname{SEM}(n=$ at least 3 replicates $)$.

activation produced by the reference compound (JWH-018), JWH-122, MAM-2201, JWH-210, EAM-2201, and their monohydroxylated metabolites.

PB-22 and 5F-PB-22. PB-22 (also named QUPIC) and 5FPB-22 belong to the quinolin-8-yl indolecarboxylate family, differing from the earlier generation naphthoylindoles by the replacement of the naphthalene group with an ester-linked quinolin-8-yl moiety (Figure 1). These compounds were first reported to the EMCDDA in November 2012 following their seizure by Finnish customs authorities. ${ }^{6}$ PB-22 and 5F-PB-22 have been implicated in clinical reports of seizure, ${ }^{54,55}$ with 5FPB-22 having been associated with several adverse reactions, comprising anxiety, paranoia, headache, vomiting, sweating, and nausea. ${ }^{56}$ 5F-PB-22 has also been detected in several fatal intoxications in the USA. ${ }^{57}$ PB-22 and 5F-PB-22 are known to be very potent $\mathrm{SCs}$, both possessing subnanomolar potency at $\mathrm{CB}$ receptors (Table 1 ), but nothing is known about the activities of their metabolites. The metabolism of PB-22 and 5F-PB-22 has primarily been investigated via in vitro metabolism studies. ${ }^{58-60}$ After examining authentic urine samples from users who consumed PB-22 and 5F-PB-22, we selected some metabolites to assess their activity at $\mathrm{CB}$ receptors. For PB-22, the 3-carboxyindole was the major phase I metabolite, with the 4-OH-pentyl metabolite usually being the second most prevalent. A similar metabolic profile was seen for 5F-PB-22, with the 3-carboxyindole as most prominent and the 5-OH-pentyl as second most abundant phase I metabolite.
The reporter assay was used to evaluate the intrinsic activity at the CB1 and CB2 receptors of PB-22, 5F-PB-22, and all of the above-mentioned metabolites, as well as that of the $\mathrm{N}$ pentanoic acid metabolite, which is also found in most urine samples (unpublished observations), all at a fixed concentration of $1 \mu \mathrm{M}$. PB-22 and 5F-PB-22 showed significantly stronger receptor activation at both $\mathrm{CB}$ receptors in comparison to the reference, JWH-018: 2.87- and 2.79-fold increases at the CB1 receptor and 1.38- and 1.32-fold increases at the $\mathrm{CB} 2$ receptor, respectively (Figure 5A,B and Supporting Information Data S6). The capability of the major phase I metabolites 3carboxyindole-PB-22 and 3-carboxyindole-5F-PB-22 to activate the $\mathrm{CB}$ receptors did not differ significantly from basal levels. There was also no antagonistic activity observed for these two compounds (Supporting Information Data S7), indicating that the 3-carboxyindole metabolites do not induce effects at the $\mathrm{CB}$ receptors. This suggests that the quinolin- 8 -yl moiety is crucial for $\mathrm{CB}$ receptor binding, just as the naphthoyl group is important for the naphthoylindoles through its aromatic stacking with the receptor. ${ }^{61}$ The second most abundant metabolites (the 4- and 5-OH-pentyl-PB-22 metabolites) showed $\mathrm{CB} 1$ receptor activation, which was significantly lower in comparison to that of PB-22, but it was still significantly higher than that induced by our reference compound, JWH-018 (208.0 and $171.0 \%$, respectively). Although PB-22, 5F-PB-22, and the hydroxylated metabolites yielded higher levels of $\mathrm{CB} 2$ receptor activation, this activation did not significantly differ from the reference compound, JWH018. The N-pentanoic acid PB-22 metabolite did show a significant activation at the $\mathrm{CB} 2$ receptor (43.5\%), just as $\mathrm{N}$ pentanoic acid JWH-210, but unexpectedly, it also showed a significant activation of the $\mathrm{CB} 1$ receptor compared to basal levels (25.8\%), although this activation remained significantly lower than that induced by JWH-018 and PB-22.

In conclusion, at the evaluated concentration, all hydroxylated metabolites of JWH-122, JWH-210, and PB-22 and their 5-fluoro analogues yielded a similar or sometimes even a significantly higher signal at the $\mathrm{CB}$ receptors than the reference agonist, JWH-018, suggesting a functional relevance for these compounds. Also, the two N-pentanoic acid metabolites of JWH-210 and PB-22 consistently showed activity at one or both $\mathrm{CB}$ receptors. This was not expected based on literature data for the $\mathrm{N}$-pentanoic acid metabolites of JWH-018 and JWH-073. ${ }^{17,18,20}$ It is known that SCs quickly reach maximum concentrations in blood upon use. A high serum concentration of JWH-018 was reached upon smoking. ${ }^{62}$ These compounds can have very long terminal half-lives (in the range of several days), as has been demonstrated in heavy, chronic users, due to extensive distribution in deeper tissue. ${ }^{63} \mathrm{~A}$ small oral single-dose self-administration pharmacokinetic study showed that the serum concentration of the metabolites exceeded that of the parent compound (AM-2201 in that case) at all time points $(1.5-21 \mathrm{~h})$, suggesting a combination of slow resorption and a fast metabolic transformation upon oral uptake. ${ }^{64}$ Although little is known about the concentrations and half-lives of the metabolites in the blood of users, the presence of active metabolites may prolong a compound's psychotropic and physiological effects, thereby contributing to its toxicity profile.

Application of the CB Reporter Assays on Natural Cannabinoids ( $\Delta^{9}$ THC and CBD) and the Main Phase I Metabolites of $\Delta^{9} \mathrm{THC}$. In addition to SCs, the natural cannabinoids $\Delta^{9} \mathrm{THC}$ and cannabidiol (CBD), as well as the 
major phase I metabolites of $\Delta^{9} \mathrm{THC}, 11-\mathrm{OH}-\mathrm{THC}$, and $\mathrm{THCCOOH}$, were evaluated in the $\mathrm{CB}$ reporter assay, all at 1 $\mu \mathrm{M}$ concentration (corresponding to $314.5,314.5,330.5$, and $344.4 \mathrm{ng} / \mathrm{mL}$, respectively). $\Delta^{9} \mathrm{THC}$ levels in urine are typically quite low (with $30 \mathrm{ng} / \mathrm{mL}$ corresponding to a very high concentration in heavy users). Urinary concentrations of 11$\mathrm{OH}-\mathrm{THC}$ and $\mathrm{THCCOOH}$ can reach up to a few hundred or a few thousand $\mathrm{ng} / \mathrm{mL}$, respectively, in cases with recent heavy use of cannabis. ${ }^{65-67}$ Taking as reference the signal obtained with $1 \mu \mathrm{M}$ JWH-018, no or only low-level activation was seen with the natural cannabinoids (Figure 6). THCCOOH shows

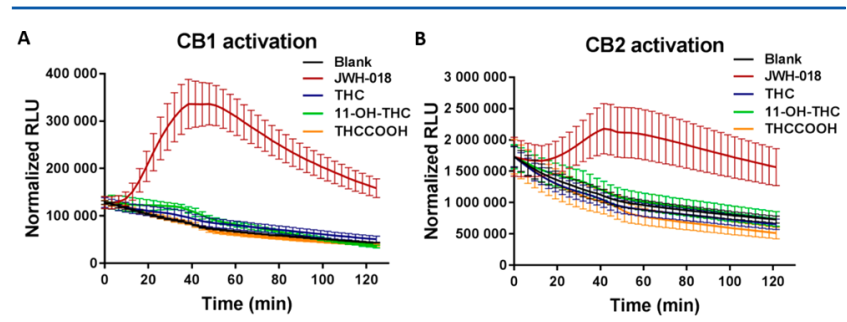

Figure 6. Activation profiles at $\mathrm{CB} 1$ (A) and $\mathrm{CB} 2$ (B) for JWH-018 (red), $\Delta^{9}$ THC (blue), 11-OH-THC (green), and $\mathrm{THCCOOH}$ (orange) at a concentration of $1 \mu \mathrm{M}$. Data are given as normalized relative light units $(\mathrm{RLU}) \pm \operatorname{SEM}(n=4$, except for JWH-018 for CB2 where $n=2$ ).

no activation at both receptors, either at 1 (Figure 6) or $10 \mu \mathrm{M}$ (3144 ng/mL; data not shown), in line with expectations. $\Delta^{9} \mathrm{THC}$ shows some activation at $\mathrm{CB} 1$ at $1 \mu \mathrm{M}$, but it does not show any activation at CB2. 11-OH-THC shows a low level of activation at $1 \mu \mathrm{M}$ at both receptors, which is more pronounced for $\mathrm{CB} 1$ compared to that for CB2. For CBD, which is found only at low concentrations in the urine of cannabis users (typically below $10 \mathrm{ng} / \mathrm{mL}$ ), ${ }^{65}$ we found no activity at both receptors at a concentration of $1 \mu \mathrm{M}$ (data not shown). However, if oral/oromucosal CBD is administered, (very) high concentrations may be obtained in the urine, ${ }^{68,69}$ which may influence the signal obtained in our reporter assay.

Application of the CB Reporter Assay as a First-Line Screening Tool in Urine: Proof of Concept. A promising future application of the newly developed $\mathrm{CB}$ reporter assay may be its deployment as a first-line screening tool, complementing targeted and untargeted analytical assays and/ or preceding analytical (mass spectrometry based) confirmation. However, the low concentrations of SCs in biological fluids require high-sensitivity bioassays capable of monitoring low-nanomolar or subnanomolar $(\mathrm{ng} / \mathrm{mL})$ levels of SCs. We therefore analyzed urine samples of two separate individuals, spiked with one of the two major metabolites of JWH-210, 4and 5-OH-pentyl-JWH-210, at a concentration of $2 \mathrm{ng} / \mathrm{mL}$ (5.2 $\mathrm{nM})$. The signals obtained for the spiked urine samples could be distinguished from the blanks in both the CB1 and CB2 bioassays (Figure $7 \mathrm{~A}-\mathrm{D}$ ).

Next, we analyzed three separate blank urine samples and a genuine urine sample from a user who had consumed a mixture of JWH-018, JWH-122, and JWH-210 (Figure 7E,F). These urine samples were split in two parts. One part was subjected to a semiquantitative LC-MS/MS method, and the other part was evaluated in our newly developed bioassay. LC-MS/MS analysis confirmed the presence of metabolites of JWH-018, JWH-122, and JWH-210 at low- or subnanomolar $(\mathrm{ng} / \mathrm{mL})$ levels, thereby confirming the intake of the aforementioned SCs (Table 2). Evaluation of the extract with our bioassay resulted in a signal
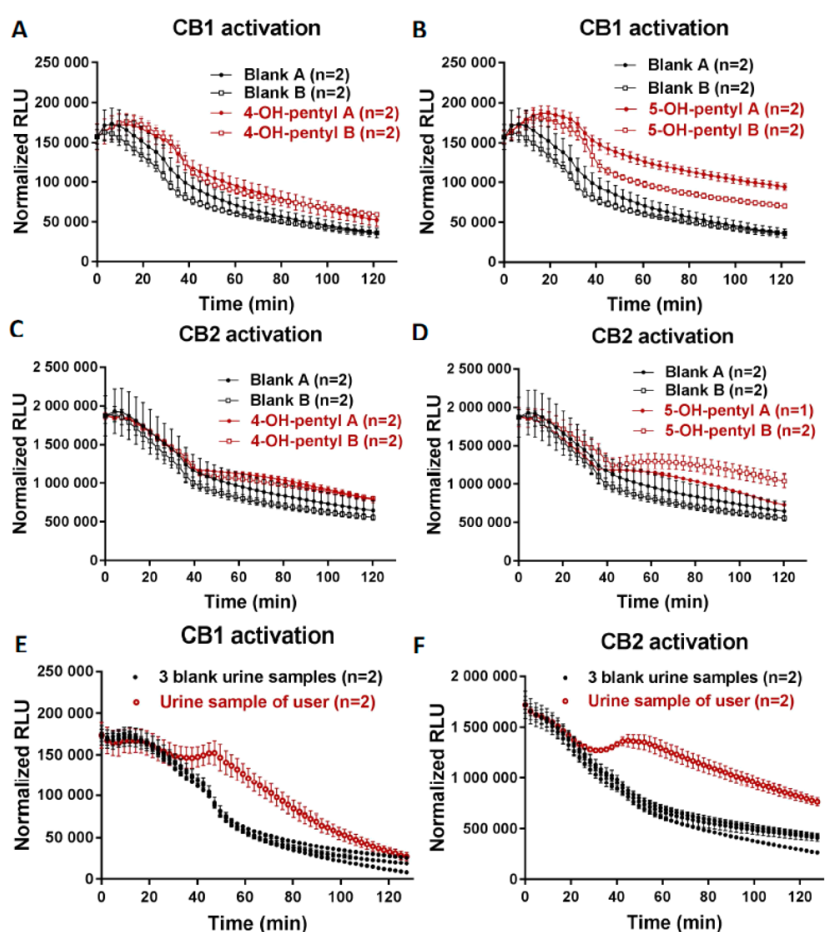

Figure 7. (A-D) Analyses of blank and spiked urine samples (2 ng/ $\mathrm{mL}$ ) of two separate individuals. Shown are the normalized raw data of the activation profiles obtained for $\mathrm{CB} 1(\mathrm{~A}, \mathrm{~B})$ and $\mathrm{CB} 2(\mathrm{C}, \mathrm{D})$ for 4OH-pentyl-JWH-210 (A, C) and 5-OH-pentyl-JWH-210 (B, D). (E, F) Analyses of three separate blank urine samples and a urine sample from a SC user via the $\mathrm{CB}$ reporter assay for CB1 (E) and CB2 (F). Data are given as normalized relative light units $(R L U) \pm S E M$.

Table 2. Semiquantitative Analysis of Urine Sample of a SC User via LC-ESI-MS/MS Analysis

\begin{tabular}{ccr} 
drug & metabolite & \multicolumn{1}{c}{ semiquantitative result } \\
JWH-018 & 4-OH-pentyl & $1.96 \mathrm{nM}(0.7 \mathrm{ng} / \mathrm{mL})$ \\
& 5-OH-pentyl & $1.12 \mathrm{nM}(0.4 \mathrm{ng} / \mathrm{mL})$ \\
JWH-122 & 4-OH-pentyl & $0.19 \mathrm{nM}(0.07 \mathrm{ng} / \mathrm{mL})$ \\
& 5-OH-pentyl & $<0.03 \mathrm{nM}(<0.01 \mathrm{ng} / \mathrm{mL})$ \\
JWH-210 & 4-OH-pentyl & $3.46 \mathrm{nM}(1.4 \mathrm{ng} / \mathrm{mL})$ \\
& 5-OH-pentyl & $0.26 \mathrm{nM}(0.1 \mathrm{ng} / \mathrm{mL})$ \\
& 5-OH-indole & $0.16 \mathrm{nM}(0.06 \mathrm{ng} / \mathrm{mL})$ \\
\hline
\end{tabular}

that could clearly be distinguished from the three control urine extracts, both for $\mathrm{CB} 1$ and $\mathrm{CB} 2$ receptors (Figure $7 \mathrm{E}, \mathrm{F}$ ). Although this result clearly needs to be extended using a larger panel of authentic samples (which is beyond the scope of the current study), it indicates the applicability of the CB reporter assay in the context of screening biological matrices.

\section{CONCLUSIONS}

We successfully developed a CB receptor activation assay based on NanoLuc binary technology. This assay combines several advantages over other $\mathrm{CB}$ receptor activation assays as it is a relatively simple, nonradioactive, sensitive, and homogeneous method, only requiring basic cell culture equipment and a standard luminometer. CB receptor activation is measured proximal to the receptor, which is known to reduce the incidence of false positives. The developed assay allows realtime monitoring of receptor activation as the measurement starts from the moment the test compound is added (which is in contrast to the commercially available PathHunter assay). 
The system is also flexible, as the $\mathrm{CB}$ receptors can be easily replaced by another GPCR. The newly developed bioassay was applied to determine the in vitro activity of several SCs and their metabolites. We observed that several major metabolites retain their activity at $\mathrm{CB}$ receptors. The high potency and efficacy of SCs, coupled with their metabolism to a number of highly active metabolites, might help to explain the distinct adverse clinical manifestations that have been observed with SC use.

When considering $\mathrm{CB}$ receptors, the developed bioassay may be used for structure-activity relationship (SAR) studies, but importantly, it may also be useful as newer NPS legislations start to implement "activity" (possibly expressed as potency and/or efficacy) rather than the identity of the drug or its chemical structure. For example, in 2012, the USA implemented a legislation that essentially illegalized all SCs as the new law broadly covers any material or mixture that contains any amount of "cannabimimetic" agents, their salts, isomers, or salts of isomers. ${ }^{70}$ Also, in the UK, a new law on "legal highs" has been implemented since May 2016. ${ }^{71}$ The Psychoactive Substances Act differs from the established approach to drug control under the Misuse of Drugs Act 1971 as it covers substances by virtue of their psychoactive properties, as defined by the Advisory Council on the Misuse of Drugs. Herein, the definition of a substance producing a psychoactive effect includes "...(a substance) which produces a response in in vitro tests qualitatively identical to substances controlled under the Misuse of Drugs Act 1971...". ${ }^{72}$ One of the receptors included in these in vitro tests, to demonstrate "psychoactivity" for the purposes of the Psychoactive Substances Act, is the CB1 receptor. ${ }^{70}$ It is clear that solely deducing activity from SAR studies will inevitably lead to discussions that can be efficiently countered by the developed bioassay.

Our data indicate that the newly developed $\mathrm{CB}$ reporter assay detects $\mathrm{CB}$ receptor activation by extracts of biological matrices in which SCs (or metabolites) are present at low- or subnanomolar levels of SCs. In the future, this may allow its deployment as a first-line screening tool, complementing targeted and untargeted analytical assays and/or preceding analytical (mass spectrometry based) confirmation. Although the SCs (and metabolites) tested here, as well as other SCs (and corresponding metabolites, unpublished observations) were found to be active, we cannot exclude at this point that there may be SCs for which the major phase I metabolites are inactive. Also, in cases where there is a considerable delay between use and sampling, with only trace levels remaining present, these trace levels may not be sufficient to generate a signal in our bioassay. However, it should be mentioned that the latter also holds true for analytical assays. For natural cannabinoids, we cannot exclude that very high urinary levels of $\Delta^{9} \mathrm{THC}$ and/or 11-OH-THC may give rise to a positive result after recent heavy cannabis use, which is not surprising as we screen for $\mathrm{CB}$ activity. In addition, oral or oromucosal use of products containing high $\mathrm{CBD}$ levels may influence the signal obtained in our $\mathrm{CB}$ reporter assay. However, in both of the above-mentioned scenarios, we expect that this will not pose a problem, as heavy use of natural cannabinoids will be easily picked up by conventional screening assays.

\section{ASSOCIATED CONTENT}

\section{Supporting Information}

The Supporting Information is available free of charge on the ACS Publications website at DOI: 10.1021/acs.analchem.6b02600.

Chemicals and reagents, plasmids and constructs, and cell culture and transfection information (S1); explanation of correction for solvent controls and for interwell variability (S2); MRM transitions and optimized MS parameters for the analytes detected in the urine samples as well as the internal standards (S3); concentrationdependent interactions of $\mathrm{CB} 1$ and $\mathrm{CB} 2$ with $\beta$ arr2 upon stimulation with different SCs (S4); literature on potency $\left(\mathrm{EC}_{50}\right)$ data for $\Delta^{9} \mathrm{THC}$ and JWH-018 (S5); comparison of the relative potential of all SCs and metabolites to activate $\mathrm{CB} 1$ and $\mathrm{CB} 2$ at $1 \mu \mathrm{M}$ (S6); antagonistic properties of several SC metabolites (S7) (PDF)

\section{AUTHOR INFORMATION}

\section{Corresponding Author}

*E-mail: christophe.stove@ugent.be. Tel.: +32 92648135. Fax: +3292648183.

\section{Notes}

The authors declare no competing financial interest.

\section{ACKNOWLEDGMENTS}

The authors acknowledge Dr. Pieter Colin, Huybrecht T'jollyn, and Robin Michelet for their help in data analysis. The skillful staff of the Laboratory of Experimental Cancer Research (headed by Prof. O. De Wever) is acknowledged for their help with cell culture in the early stages of this project. The Agency for Innovation by Science and Technology (IWT-Flanders) and the Bijzonder Onderzoeksfonds (BOF) of Ghent University are acknowledged for, respectively, granting a Grant for Strategic Basic Research to A. Cannaert (application number 121504) and a Ph.D. fellowship to J. Storme (application number 01D31913). The research activities of the Institute of Forensic Medicine Freiburg were financially supported by the 'Prevention of and Fight against Crime' program of the European Commission (JUST/2013/ISEC/DRUGS/AG/ 6421).

\section{REFERENCES}

(1) European Drug Report: Trends and Developments; EMCDDA: Lisbon, Portugal, 2016.

(2) Fantegrossi, W. E.; Moran, J. H.; Radominska-Pandya, A.; Prather, P. L. Life Sci. 2014, 97, 45-54.

(3) Vardakou, I.; Pistos, C.; Spiliopoulou, C. Toxicol. Lett. 2010, 197, $157-62$.

(4) Seely, K. A.; Lapoint, J.; Moran, J. H.; Fattore, L. Prog. NeuroPsychopharmacol. Biol. Psychiatry 2012, 39, 234-43.

(5) Auwärter, V.; Dresen, S.; Weinmann, W.; Müller, M.; Pütz, M.; Ferreiros, N. J. Mass Spectrom. 2009, 44, 832-7.

(6) European Monitoring Centre for Drugs and Drug Addiction Drug Report; EMCDDA: Lisbon, Portugal, 2015.

(7) Castaneto, M. S.; Gorelick, D. A.; Desrosiers, N. A.; Hartman, R. L.; Pirard, S.; Huestis, M. A. Drug Alcohol Depend. 2014, 144, 12-41.

(8) Pertwee, R. G.; Ross, R. A. Prostaglandins, Leukotrienes Essent. Fatty Acids 2002, 66, 101-21.

(9) Van Sickle, M. D.; Duncan, M.; Kingsley, P. J.; Mouihate, A.; Urbani, P.; Mackie, K.; Stella, N.; Makriyannis, A.; Piomelli, D.; Davison, J. S.; Marnett, L. J.; Di Marzo, V.; Pittman, Q. J.; Patel, K. D.; Sharkey, K. A. Science 2005, 310 (5746), 329-32. 
(10) Onaivi, E. S.; Ishiguro, H.; Gong, J. P.; Patel, S.; Meozzi, P. A.; Myers, L.; Perchuk, A.; Mora, Z.; Tagliaferro, P. A.; Gardner, E.; Brusco, A.; Akinshola, B. E.; Hope, B.; Lujilde, J.; Inada, T.; Iwasaki, S.; Macharia, D.; Teasenfitz, L.; Arinami, T.; Uhl, G. R. PLoS One 2008, 3, e1640.

(11) Howlett, A. C.; Barth, F.; Bonner, T. I.; Cabral, G.; Casellas, P.; Devane, W. A.; Felder, C. C.; Herkenham, M.; Mackie, K.; Martin, B. R.; Mechoulam, R.; Pertwee, R. G. Pharmacol Rev. 2002, 54, 161-202.

(12) Winstock, A.; Lynskey, M.; Borschmann, R.; Waldron, J. J. Psychopharmacol. 2015, 29, 698-703.

(13) Tait, R. J.; Caldicott, D.; Mountain, D.; Hill, S. L.; Lenton, S. Clin. Toxicol. 2016, 54, 1-13.

(14) Gunderson, E. W.; Haughey, H. M.; Ait-Daoud, N.; Joshi, A. S.; Hart, C. L. Am. J. Addict 2012, 21, 320-6.

(15) Huestis, M. A. Chem. Biodiversity 2007, 4, 1770-804.

(16) Banister, S. D.; Stuart, J.; Kevin, R. C.; Edington, A.; Longworth, M.; Wilkinson, S. M.; Beinat, C.; Buchanan, A. S.; Hibbs, D. E.; Glass, M.; Connor, M.; McGregor, I. S.; Kassiou, M. ACS Chem. Neurosci. 2015, 6, 1445-58.

(17) Brents, L. K.; Gallus-Zawada, A.; Radominska-Pandya, A.; Vasiljevik, T.; Prisinzano, T. E.; Fantegrossi, W. E.; Moran, J. H.; Prather, P. L. Biochem. Pharmacol. 2012, 83, 952-61.

(18) Brents, L. K.; Reichard, E. E.; Zimmerman, S. M.; Moran, J. H.; Fantegrossi, W. E.; Prather, P. L. PLoS One 2011, 6, e21917.

(19) Chimalakonda, K. C.; Seely, K. A.; Bratton, S. M.; Brents, L. K.; Moran, C. L.; Endres, G. W.; James, L. P.; Hollenberg, P. F.; Prather, P. L.; Radominska-Pandya, A.; Moran, J. H. Drug Metab. Dispos. 2012, 40, 2174-84.

(20) Rajasekaran, M.; Brents, L. K.; Franks, L. N.; Moran, J. H.; Prather, P. L. Toxicol. Appl. Pharmacol. 2013, 269, 100-8.

(21) Breivogel, C. S.; Griffin, G.; Di Marzo, V.; Martin, B. R. Mol. Pharmacol. 2001, 60, 155-63.

(22) De Luca, M. A.; Castelli, M. P.; Loi, B.; Porcu, A.; Martorelli, M.; Miliano, C.; Kellett, K.; Davidson, C.; Stair, L. J.; Schifano, F.; Di Chiara, G. Neuropharmacology 2016, 105, 630-8.

(23) Huffman, J. W.; Szklennik, P. V.; Almond, A.; Bushell, K.; Selley, D. E.; He, H.; Cassidy, M. P.; Wiley, J. L.; Martin, B. R. Bioorg. Med. Chem. Lett. 2005, 15, 4110-3.

(24) Nakajima, J.; Takahashi, M.; Nonaka, R.; Seto, T.; Suzuki, J.; Yoshida, M.; Kanai, C.; Hamano, T. Forensic Toxicol. 2011, 29, 132141.

(25) Wiley, J. L.; Marusich, J. A.; Lefever, T. W.; Grabenauer, M.; Moore, K. N.; Thomas, B. F. Neuropharmacology 2013, 75, 145-54.

(26) Seely, K. A.; Brents, L. K.; Radominska-Pandya, A.; Endres, G. W.; Keyes, G. S.; Moran, J. H.; Prather, P. L. Chem. Res. Toxicol. 2012, $25,825-7$.

(27) Atwood, B. K.; Huffman, J.; Straiker, A.; Mackie, K. Br. J. Pharmacol. 2010, 160, 585-93.

(28) Atwood, B. K.; Lee, D.; Straiker, A.; Widlanski, T. S.; Mackie, K. Eur. J. Pharmacol. 2011, 659 (2-3), 139-45.

(29) Slipetz, D. M.; O’Neill, G. P.; Favreau, L.; Dufresne, C.; Gallant, M.; Gareau, Y.; Guay, D.; Labelle, M.; Metters, K. M. Mol. Pharmacol. 1995, 48, 352-61.

(30) Yao, B. B.; Mukherjee, S.; Fan, Y.; Garrison, T. R.; Daza, A. V.; Grayson, G. K.; Hooker, B. A.; Dart, M. J.; Sullivan, J. P.; Meyer, M. D. Br. J. Pharmacol. 2006, 149, 145-54.

(31) Banister, S. D.; Moir, M.; Stuart, J.; Kevin, R. C.; Wood, K. E.; Longworth, M.; Wilkinson, S. M.; Beinat, C.; Buchanan, A. S.; Glass, M.; Connor, M.; McGregor, I. S.; Kassiou, M. ACS Chem. Neurosci. 2015, 6, 1546-59.

(32) McGuinness, D.; Malikzay, A.; Visconti, R.; Lin, K.; Bayne, M.; Monsma, F.; Lunn, C. A. J. Biomol. Screening 2008, 14, 49-58.

(33) van der Lee, M. M.; Blomenrohr, M.; van der Doelen, A. A.; Wat, J. W.; Smits, N.; Hanson, B. J.; van Koppen, C. J.; Zaman, G. J. J. Biomol. Screening 2009, 14, 811-23.

(34) Milligan, G. Trends Pharmacol. Sci. 2003, 24, 87-90.

(35) Thomsen, W.; Frazer, J.; Unett, D. Curr. Opin. Biotechnol. 2005, $16,655-65$.

(36) Zhang, R.; Xie, X. Acta Pharmacol. Sin. 2012, 33, 372-84.
(37) Bohn, L. M.; McDonald, P. H. Drug Discovery Today: Technol. 2010, 7, e37-e42.

(38) Dixon, A. S.; Schwinn, M. K.; Hall, M. P.; Zimmerman, K.; Otto, P.; Lubben, T. H.; Butler, B. L.; Binkowski, B. F.; Machleidt, T.; Kirkland, T. A.; Wood, M. G.; Eggers, C. T.; Encell, L. P.; Wood, K. V. ACS Chem. Biol. 2016, 11, 400-8.

(39) Franz, F.; Angerer, V.; Hermanns-Clausen, M.; Auwärter, V.; Moosmann, B. Anal. Bioanal. Chem. 2016, 408, 3445-52.

(40) Lohse, M. J.; Benovic, J. L.; Codina, J.; Caron, M. G.; Lefkowitz, R. J. Science 1990, 248, 1547-50.

(41) Ferguson, S. S.; Downey, W. E., 3rd; Colapietro, A. M.; Barak, L. S.; Menard, L.; Caron, M. G. Science 1996, 271, 363-6.

(42) Ferguson, S. S. Pharmacol Rev. 2001, 53, 1-24.

(43) Chu, C. M.; Hung, M. S.; Hsieh, M. T.; Kuo, C. W.; Suja, T. D.; Song, J. S.; Chiu, H. H.; Chao, Y. S.; Shia, K. S. Org. Biomol. Chem. 2008, 6, 3399-407.

(44) Chimalakonda, K. C.; Moran, C. L.; Kennedy, P. D.; Endres, G. W.; Uzieblo, A.; Dobrowolski, P. J.; Fifer, E. K.; Lapoint, J.; Nelson, L. S.; Hoffman, R. S.; James, L. P.; Radominska-Pandya, A.; Moran, J. H. Anal. Chem. 2011, 83, 6381-8.

(45) Moran, C. L.; Le, V. H.; Chimalakonda, K. C.; Smedley, A. L.; Lackey, F. D.; Owen, S. N.; Kennedy, P. D.; Endres, G. W.; Ciske, F. L.; Kramer, J. B.; Kornilov, A. M.; Bratton, L. D.; Dobrowolski, P. J.; Wessinger, W. D.; Fantegrossi, W. E.; Prather, P. L.; James, L. P.; Radominska-Pandya, A.; Moran, J. H. Anal. Chem. 2011, 83, 4228-36.

(46) Sobolevsky, T.; Prasolov, I.; Rodchenkov, G. Forensic Sci. Int. 2010, 200, 141-7.

(47) Shanks, K. G.; Behonick, G. S.; Dahn, T.; Terrell, A. J. Anal. Toxicol. 2013, 37, 517-25.

(48) Shanks, K. G.; Dahn, T.; Behonick, G.; Terrell, A. J. Anal. Toxicol. 2012, 36, 360-71.

(49) Hermanns-Clausen, M.; Kithinji, J.; Spehl, M.; Angerer, V.; Franz, F.; Eyer, F.; Auwärter, V. Drug Test. Anal. 2016, 8, 1030-8.

(50) Hermanns-Clausen, M.; Kneisel, S.; Szabo, B.; Auwärter, V. Addiction 2013, 108, 534-44.

(51) Saito, T.; Namera, A.; Miura, N.; Ohta, S.; Miyazaki, S.; Osawa, M.; Inokuchi, S. Forensic Toxicol. 2013, 31, 333-7.

(52) Derungs, A.; Schwaninger, A. E.; Mansella, G.; Bingisser, R.; Kraemer, T.; Liechti, M. E. Forensic Toxicol. 2013, 31, 164-171.

(53) Jang, M.; Shin, I.; Yang, W.; Chang, H.; Yoo, H. H.; Lee, J.; Kim, E. Forensic Sci. Int. 2014, 244, 85-91.

(54) Gugelmann, H.; Gerona, R.; Li, C.; Tsutaoka, B.; Olson, K. R.; Lung, D. Clin. Toxicol. 2014, 52, 635-8.

(55) Schep, L. J.; Slaughter, R. J.; Hudson, S.; Place, R.; Watts, M. Hum. Exp. Toxicol. 2015, 34, 557-60.

(56) Santacroce, R.; Corazza, O.; Martinotti, G.; Bersani, F. S.; Valeriani, G.; Di Giannantonio, M. Hum. Psychopharmacol. 2015, 30, 265-71.

(57) Behonick, G.; Shanks, K. G.; Firchau, D. J.; Mathur, G.; Lynch, C. F.; Nashelsky, M.; Jaskierny, D. J.; Meroueh, C. J. Anal. Toxicol. 2014, 38 (8), 559-62.

(58) Takayama, T.; Suzuki, M.; Todoroki, K.; Inoue, K.; Min, J. Z.; Kikura-Hanajiri, R.; Goda, Y.; Toyo'oka, T. Biomed. Chromatogr. 2014, $28,831-8$.

(59) Thomsen, R.; Nielsen, L. M.; Holm, N. B.; Rasmussen, H. B.; Linnet, K. Drug Test. Anal. 2015, 7, 565-76.

(60) Wohlfarth, A.; Gandhi, A. S.; Pang, S.; Zhu, M.; Scheidweiler, K. B.; Huestis, M. A. Anal. Bioanal. Chem. 2014, 406 (6), 1763-80.

(61) Wiley, J. L.; Marusich, J. A.; Huffman, J. W. Life Sci. 2014, 97, $55-63$.

(62) Teske, J.; Weller, J. P.; Fieguth, A.; Rothamel, T.; Schulz, Y.; Troger, H. D. J. Chromatogr. B: Anal. Technol. Biomed. Life Sci. 2010, 878, 2659-63.

(63) Kneisel, S.; Teske, J.; Auwärter, V. Drug Test. Anal. 2014, 6, $135-6$.

(64) Hutter, M.; Moosmann, B.; Kneisel, S.; Auwärter, V. J. Mass Spectrom. 2013, 48, 885-94. 
(65) Aizpurua-Olaizola, O.; Zarandona, I.; Ortiz, L.; Navarro, P.; Etxebarria, N.; Usobiaga, A. Drug Test. Anal. 2016, DOI: 10.1002/ dta.1998.

(66) Lowe, R. H.; Abraham, T. T.; Darwin, W. D.; Herning, R.; Cadet, J. L.; Huestis, M. A. Drug Alcohol Depend. 2009, 105 (1-2), 24-32.

(67) Fraser, A. D.; Worth, D. Forensic Sci. Int. 2004, 143 (2-3), 14752.

(68) Bergamaschi, M. M.; Barnes, A.; Queiroz, R. H.; Hurd, Y. L.; Huestis, M. A. Anal. Bioanal. Chem. 2013, 405 (14), 4679-89.

(69) Kevin, R. C.; Allsop, D. J.; Lintzeris, N.; Dunlop, A. J.; Booth, J.; McGregor, I. S. Forensic Toxicol. 2016, 1-12.

(70) Food and Drug Administration Safety and Innovation Act: Synthetic Drug Abuse Prevention Act, Sections 1151-1153, 2012.

(71) Psychoactive Substances Act 2016, TSO: Norwich, UK, 2016; Chapter 2, pp 1-57.

(72) Psychoactive Substances Act 2016: Forensic Strategy; AMCD, 2016; pp 1-10. 


\title{
Supporting Information
}

\section{Detection and activity profiling of synthetic cannabinoids and metabolites with a newly developed bio-assay}

\author{
Annelies Cannaert ${ }^{1}$, Jolien M. Storme ${ }^{1}$, Florian Franz ${ }^{2}$, Volker Auwärter ${ }^{2}$, Christophe P. Stove ${ }^{1}$ \\ ${ }^{1}$ Laboratory of Toxicology, Department of Bioanalysis, Faculty of Pharmaceutical Sciences, Ghent \\ University, Ottergemsesteenweg 460, 9000 Ghent, Belgium \\ ${ }^{2}$ Institute of Forensic Medicine, Forensic Toxicology, Medical Center - University of Freiburg, Faculty \\ of Medicine, University of Freiburg, Albertstr. 9, 79104 Freiburg, Germany
}

\section{CONTENT}

Page 2 Supplementary Data S-1

Chemicals and reagents, plasmids and constructs, cell culture and transfection

\section{Page 5 Supplementary Data S-2}

Explanation of correction for solvent controls and for inter-well variability

\section{Page 6 Supplementary Data S-3}

Supporting table showing MRM transitions and optimized MS parameters for the analytes detected in the urine samples and the used internal standards.

Page 8 Supplementary Data S-4

Concentration-dependent interaction of CB1 and $\mathrm{CB} 2$ with $\beta$ arr2 upon stimulation with different SCS

Page 9 Supplementary Data S-5

Potency $\left(\mathrm{EC}_{50}\right)$ of $\Delta^{9} \mathrm{THC}$ and JWH-018, determined by different functional assays

Page 10 Supplementary Data S-6

Comparison of relative potential to activate $\mathrm{CB} 1$ and $\mathrm{CB} 2$ at $1 \mu \mathrm{M}$

Page 11 Supplementary Data S-7

Evaluation of antagonistic properties of several SC metabolites 


\section{Supplementary Data S-1}

\section{Chemicals and reagents}

Dulbecco's modified eagle's medium (DMEM), Opti-MEM ${ }^{\circ}$ I Reduced Serum Medium, penicillin/streptomycin $(10.000 \mathrm{IU} / \mathrm{ml}$ and $10.000 \mu \mathrm{g} / \mathrm{ml})$, amphotericin $\mathrm{B}(250 \mu \mathrm{g} / \mathrm{ml})$, glutamine (200mM), the restriction enzymes Xhol and EcoRI and the DNA polymerase (Phusion polymerase, a polymerase with proofreading activity) were purchased from Thermo Fisher Scientific (Pittsburg, PA, USA). The transfection reagent FUGENE ${ }^{\circledR}$ HD and the Nano-Glo Live Cell reagent were purchased from Promega (Madison, WI, USA). Primers were procured from Eurofins Genomics (Ebersberg, Germany). JWH-122 ((4-methyl-1-naphthyl)-(1-pentyl-1H-lindol-3-yl)methanone), JWH-210 ((4-ethyl-1naphthyl)-(1-pentyl-1H-indol-3-yl)methanone), PB-22 (1-pentyl-1H-indole-3-carboxylic acid 8quinolinyl ester), their 5-fluoro analogues MAM-2201, EAM-2201, 5F-PB-22, their metabolites and all deuterated standards were supplied by Cayman Chemical (Ann Arbor, MI, USA), except JWH-018 (naphthyl(1-pentyl-1H-indol-3-yl)methanone) was obtained from LGC (Wesel, Germany) and 5-OHpentyl-JWH-018 and N-pentanoic acid JWH-018 were purchased from Sigma Aldrich. Fetal bovine serum (FBS), poly-D-lysine, formic acid (Rotipuran $\geq 98 \%$, p.a.), potassium hydrogen phosphate ( $\geq$ $99 \%$, p.a.), 2-propanol (Rotisolv ${ }^{\bullet} \geq 98 \%$, p.a.), acetonitrile (LC-MS grade), ammonium formate $10 \mathrm{M}$ $(99,995 \%)$ and potassium hydroxide (puriss. p.a. $\geq 86 \%$ (T) pellets) were from Sigma Aldrich (Steinheim, Germany). Roche Diagnostics (Mannheim, Germany) supplied the 6 -glucuronidase (E. coli K 12). Deionized water was prepared using a Medica ${ }^{\circ}$ Pro deionizer from ELGA (Celle, Germany). Blank urine samples were donated by one volunteer and tested for the absence of synthetic cannabinoid metabolites prior to use. Mobile phase A $0.2 \%$ formic acid and $2 \mathrm{mM}$ ammonium formate in water) was freshly prepared prior to LC-MS/MS analysis. Mobile phase B was pure acetonitrile.

\section{Plasmids and constructs}

Plasmids containing the human CNR1 (NM_016083) and ARRB2 (NM_004313) coding sequences were purchased from Origene Technologies (Rockville, MD, USA). A plasmid containing the human CNR2 (NM_001841) coding sequence and the expression vectors, NB MCS-1, NB MCS-2, NB MCS-3 and NB MCS-4 were kindly provided by respectively, Atwood et al. and Promega (Madison, WI, USA). The expression vectors contain the sequences encoding the subunits of the NanoLuc luciferase (LgBiT or SmBiT) and the flexible linker (GSSGGGGSGGGGSSG). All expression plasmids were constructed by cloning PCR products, flanked by a unique restriction site, into the respective vectors, as described below. All constructs were sequence-verified. 
To generate the constructs, specific primers were used to PCR-amplify the coding sequence of interest, flanked by Xhol or EcoRI restriction sites (see Table S-1a). PCR was performed on $100 \mathrm{pg}$ of plasmid DNA using the Phusion High-Fidelity PCR Master Mix with HF Buffer (Thermo Fisher Scientific, Pittsburg, PA, USA) according to the manufacturer's instructions. Reactions were done in a Mastercycler ${ }^{\mathrm{TM}}$ Nexus Thermal Cycler (Eppendorf, Hamburg, Germany) with an initial denaturation at $98^{\circ} \mathrm{C}$ for $30 \mathrm{~s}, 35$ cycles of $98^{\circ} \mathrm{C}$ for $10 \mathrm{~s}$ (denaturation), $\mathrm{T}_{\mathrm{m}}$ for $30 \mathrm{~s}$ (annealing), and $72^{\circ} \mathrm{C}$ for $1 \mathrm{~min}$ (elongation), followed by a final extension at $72^{\circ} \mathrm{C}$ for $5 \mathrm{~min}$. The resulting amplification products were purified using E.Z.N.A. ${ }^{\bullet}$ MicroElute Cycle-Pure kit (VWR International, Radnor, PA, USA). Both the vector and the amplification products were digested with either Xhol or EcoRI restriction enzymes (Thermo Fisher Scientific) and purified using E.Z.N.A. MicroElute Gel Extraction kit (VWR International). The digested PCR products were ligated into the corresponding dephosphorylated (TSAP Thermosensitive Alkaline Phosphatase, Promega), digested vector (see Table S-1b). After transformation of One Shot ${ }^{\circ}$ Mach1 ${ }^{\mathrm{TM}}$ T1 Phage-Resistant Chemically Competent E. coli (Thermo Fisher Scientific) with the ligated product, the ampicillin-resistant clones were screened by PCR using primers complementary to sequences within the insert and sequences of the vector surrounding the insert. The integrity of all constructs was confirmed by DNA sequencing. Positively screened colonies were grown and used for plasmid isolation, using E.Z.N.A. Plasmid DNA Mini kit (VWR International).

\begin{tabular}{|l|l|l|l|l|}
\hline Vector & POI & Primers & $\mathbf{T}_{\mathrm{m}}\left({ }^{\circ} \mathrm{C}\right)$ \\
\hline \multirow{3}{*}{$\begin{array}{l}\text { NB MCS-1 } \\
\text { NB MCS-2 }\end{array}$} & CB1 & Forward & ACTCAA CTCGAG ACC ATGAAGTCGATCC & 69.6 \\
\cline { 2 - 5 } & & Reverse & ACTCAA CTCGAG CC CAGAGCCTCGGC & 71.0 \\
\cline { 2 - 6 } & CB2 & Forward & ACTCAA CTCGAG CC CAGAGCCTCGGC & 71.1 \\
\cline { 2 - 6 } & & Reverse & ACTCAA CTCGAG CC GCAATCAGAGAGG & 69.7 \\
\cline { 2 - 6 } & Barr2 & Forward & ACTCAA GAATC ACC ATGGGGGAGAAACCCGGGACC & \\
\hline \multirow{2}{*}{$\begin{array}{l}\text { NB MCS-3 } \\
\text { NB MCS-4 }\end{array}$} & Reverse & ACTCAA GAATTC CC GCAGAGTTGATCATCATAGTCG & \\
\hline
\end{tabular}

Table S-1a. Primers used to clone the protein of interest (POI) in the expression plasmids. Six extra nucleotides precede the restriction site (underlined). In some primers, extra nucleotides were added to correct the reading frame. Also the Kozak sequence or stop codon (bold) were added, if necessary. The nucleotides in italics are the coding sequences of the POI.

\begin{tabular}{|l|l|l|l|}
\hline Vector & Fusion protein & POI & Restriction enzyme \\
\hline NB MCS-1 & POl - Linker - LgBiT & CB1 & Xhol \\
\hline & & CB2 & Xhol \\
\hline NB MCS-2 & POI - Linker - SmBiT & CBarr2 & EcoRl \\
\hline & & CB2 & Xhol \\
\hline & & $\beta a r r 2$ & EcoRl \\
\hline NB MCS-3 & LgBiT - Linker - POI & Barr2 & EcoRl \\
\hline NB MCS-4 & SmBiT - Linker - POI & Barr2 & EcoRl \\
\hline
\end{tabular}

Table S-1b. Lay-out of the expression vectors and restriction enzymes used for each protein of interest (POI). 


\section{Cell culture and transfection}

Human embryonic kidney (HEK) $293 \mathrm{~T}$ cells were routinely maintained at $37^{\circ} \mathrm{C}, 5 \% \mathrm{CO}_{2}$, under humidified atmosphere in DMEM (high glucose) supplemented with $10 \%$ heat-inactivated FBS, $2 \mathrm{mM}$ of glutamine, $100 \mathrm{IU} / \mathrm{ml}$ of penicillin, $100 \mu \mathrm{g} / \mathrm{ml}$ of streptomycin and $0.25 \mu \mathrm{g} / \mathrm{ml}$ of amphotericin B. For experiments, HEK 293T cells were plated in 6 -well plates at $5 \times 10^{5}$ cells/well. The next day, cells were transiently transfected using FuGENE ${ }^{\bullet}$ HD reagent according to the manufacturer's protocol (optimal ratio of FuGENE:DNA 3:1). Transfection mixes contained 1.65 $\mu$ g of each of the plasmids of interest. On the third day, cells were plated on poly-D-lysine-coated 96 -well plates at $5 \times 10^{4}$ cells/well and incubated overnight. 


\section{Supplementary Data S-2}

\section{To evaluate the activity of the different SCs and their metabolites}

To determine the activity of a compound, the absolute signals were corrected for solvent controls and for inter-well variability. First, the absolute raw signals (colored lines) were baseline-corrected by subtracting the average of the signals from vehicle control samples (black lines) (A to B). Next the signals were corrected for the inter-well variability by forcing the curve through 0 ( $B$ to $C$ ). The AUC were calculated and normalized by the AUC of the reference compound, JWH-018.
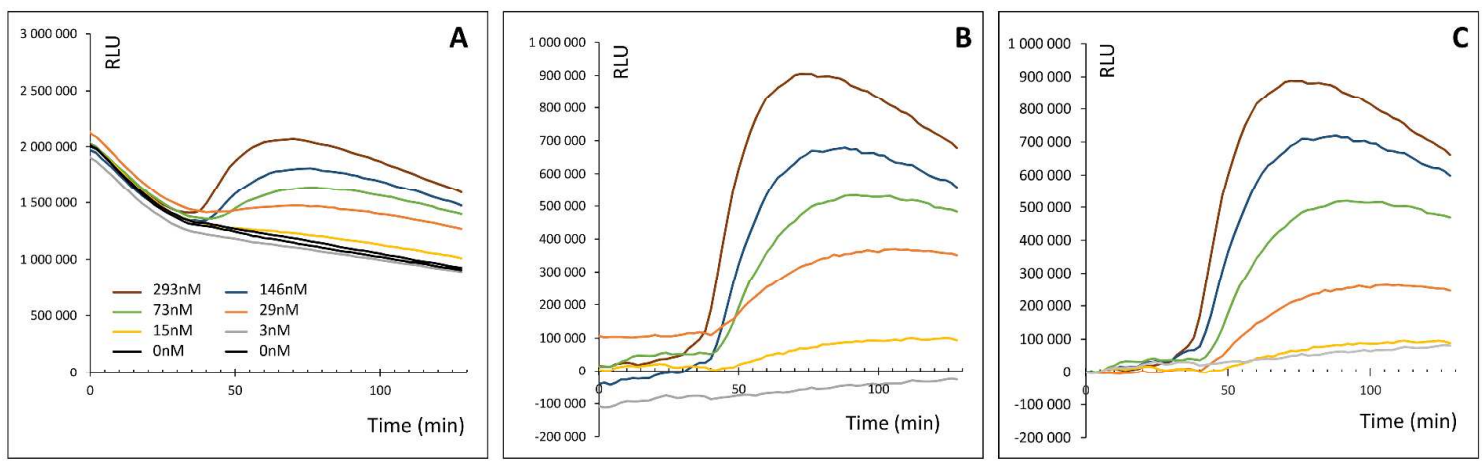

Figure S-2a: Example of solvent control and inter-well correction.

\section{To assess the activity of the natural cannabinoids and the urinary samples}

Here the absolute raw signals were only corrected for the inter-well variability. The absolute signals were corrected by forcing all the curves through the same starting point at time point 0 ( $A$ to $B$ ).
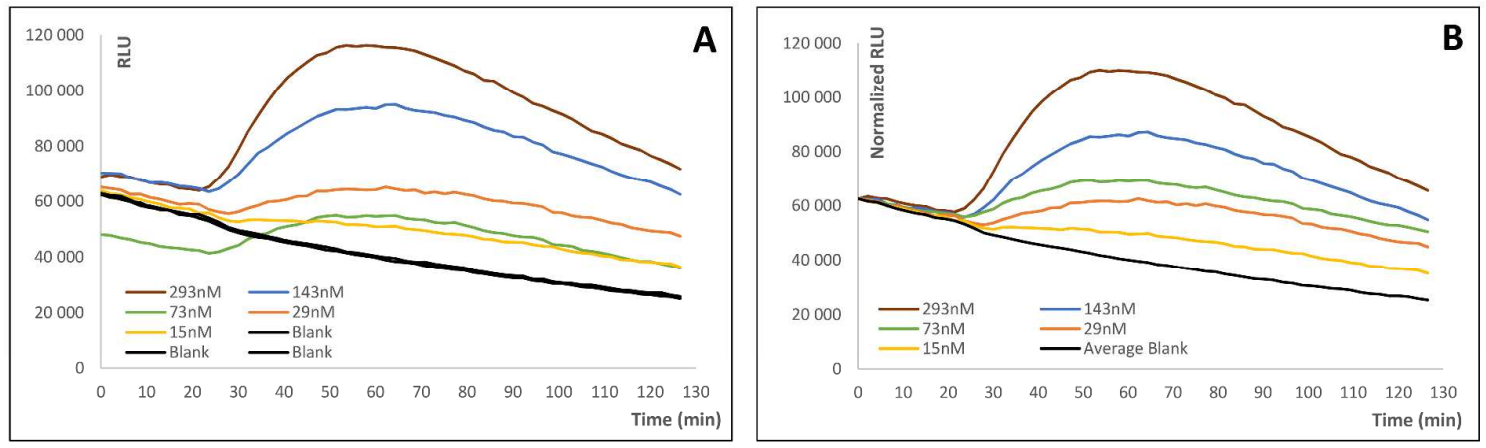

Figure S-2b: Example of inter-well correction. 


\section{Supplementary Data S-3}

Supporting table showing MRM transitions and optimized MS parameters for the analytes detected in the urine samples and the used internal standards.

\begin{tabular}{|c|c|c|c|c|c|c|c|}
\hline Analyte & $\begin{array}{c}\text { Q1 } \\
\text { [amu] }\end{array}$ & $\begin{array}{c}\text { Q3 } \\
\text { [amu] }\end{array}$ & $\begin{array}{l}\text { DP } \\
{[V]}\end{array}$ & $\begin{array}{l}\text { EP } \\
{[V]}\end{array}$ & $\begin{array}{l}\text { CE } \\
\text { [V] }\end{array}$ & $\begin{array}{l}\text { CXP } \\
\text { [V] }\end{array}$ & Internal standard \\
\hline \multirow[t]{2}{*}{ JWH-018 4-OH-pentyl } & 358 & 155 & 150 & 5 & 30 & 15 & D5-JWH-018 4-OH-pentyl \\
\hline & 358 & 127 & 150 & 5 & 65 & 15 & \\
\hline \multirow[t]{2}{*}{ JWH-018 5-OH-pentyl } & 358 & 155 & 150 & 5 & 30 & 15 & D5-JWH-018 5-OH-pentyl \\
\hline & 358 & 127 & 150 & 5 & 65 & 15 & \\
\hline \multirow[t]{2}{*}{ JWH-122 4-OH-pentyl } & 372 & 169 & 160 & 7 & 30 & 12 & D5-JWH-122 5-OH-pentyl \\
\hline & 372 & 141 & 160 & 7 & 57 & 16 & \\
\hline \multirow[t]{2}{*}{ JWH-122 5-OH-pentyl } & 372 & 169 & 160 & 7 & 30 & 12 & D5-JWH-122 5-OH-pentyl \\
\hline & 372 & 141 & 160 & 7 & 57 & 16 & \\
\hline \multirow[t]{2}{*}{ JWH-122 N-pentanoic acid } & 386 & 169 & 190 & 4 & 35 & 13 & D4-JWH-018 N-pentanoic acid \\
\hline & 386 & 141 & 190 & 4 & 61 & 11 & \\
\hline \multirow[t]{2}{*}{ MAM-2201 4-OH-pentyl } & 390 & 169 & 160 & 11 & 35 & 20 & D5-JWH-018 5-OH-pentyl \\
\hline & 390 & 141 & 160 & 11 & 65 & 22 & \\
\hline \multirow[t]{2}{*}{ JWH-210 4-OH-pentyl } & 386 & 183 & 160 & 5 & 31 & 15 & D7-JWH-018 6-OH-indole \\
\hline & 386 & 153 & 160 & 5 & 50 & 13 & \\
\hline \multirow[t]{2}{*}{ JWH-210 5-OH-indole } & 386 & 183 & 180 & 4 & 32 & 16 & D5-JWH-250 \\
\hline & 386 & 230 & 180 & 4 & 32 & 18 & \\
\hline \multirow[t]{2}{*}{ JWH-210 5-OH-pentyl } & 386 & 183 & 160 & 5 & 31 & 15 & D7-JWH-018 6-OH-indole \\
\hline & 386 & 153 & 160 & 5 & 50 & 13 & \\
\hline \multirow[t]{2}{*}{ JWH-210 N-pentanoic acid } & 400 & 183 & 160 & 11 & 35 & 14 & D7-JWH-073 6-OH-indole \\
\hline & 400 & 155 & 160 & 11 & 55 & 20 & \\
\hline \multirow[t]{2}{*}{ PB-22 3-carboxyindole } & 232 & 132 & 130 & 3 & 29 & 16 & D7-JWH-073 6-OH-indole \\
\hline & 232 & 118 & 130 & 3 & 30 & 14 & \\
\hline \multirow[t]{2}{*}{ PB-22 4-OH-pentyl } & 375 & 144 & 110 & 5 & 35 & 23 & D5-JWH-073 N-butanoic acid \\
\hline & 375 & 69 & 110 & 5 & 55 & 15 & \\
\hline \multirow[t]{2}{*}{ PB-22 5-OH-pentyl } & 375 & 230 & 110 & 6 & 45 & 15 & D5-JWH-073 N-butanoic acid \\
\hline & 375 & 144 & 110 & 5 & 35 & 23 & \\
\hline \multirow[t]{2}{*}{ PB-22 N-pentanoic acid } & 389 & 244 & 140 & 4 & 30 & 16 & D5-JWH-073 N-butanoic acid \\
\hline & 389 & 144 & 140 & 4 & 48 & 16 & \\
\hline \multirow[t]{2}{*}{ 5F-PB-22 3-carboxyindole } & 250 & 206 & 110 & 3 & 22 & 16 & D5-JWH-250 4-OH-pentyl 1 \\
\hline & 250 & 118 & 110 & 3 & 26 & 13 & \\
\hline D5-JWH-018 4-OH-pentyl & 363 & 155 & 180 & 4 & 25 & 11 & --- \\
\hline D5-JWH-018 5-OH-pentyl & 363 & 155 & 165 & 10 & 33 & 12 & --- \\
\hline D7-JWH-018 6-OH-indole & 367 & 155 & 180 & 4 & 35 & 12 & --- \\
\hline D4-JWH-018 N-pentanoic acid & 376 & 155 & 170 & 10 & 35 & 7 & --- \\
\hline D7-JWH-073 6-OH-indole & 351 & 155 & 170 & 6 & 35 & 12 & --- \\
\hline D5-JWH-073 N-butanoic acid & 363 & 155 & 190 & 5 & 35 & 11 & --- \\
\hline D5-JWH-122 5-OH-pentyl & 377 & 169 & 185 & 5 & 29 & 14 & --- \\
\hline D5-JWH-250 & 341 & 121 & 175 & 10 & 30 & 8 & --- \\
\hline D5-JWH-250 4-OH-pentyl & 357 & 121 & 150 & 8 & 31 & 15 & --- \\
\hline
\end{tabular}


Q1 $m / z$ of the precursor ion

Q2 $m / z$ of the fragment ion

DP declustering potential

EP entrance potential

CE collision energy

CXP collision cell exit potential 


\section{Supplementary Data S-4}

Graphs show the concentration-dependent interaction of $C B 1$ (A) and CB2 (B) with Barr2 upon stimulation with different SCs. AUC, area under the curve. Data are given as mean AUC \pm SEM ( $n=5$ -

$6)$.
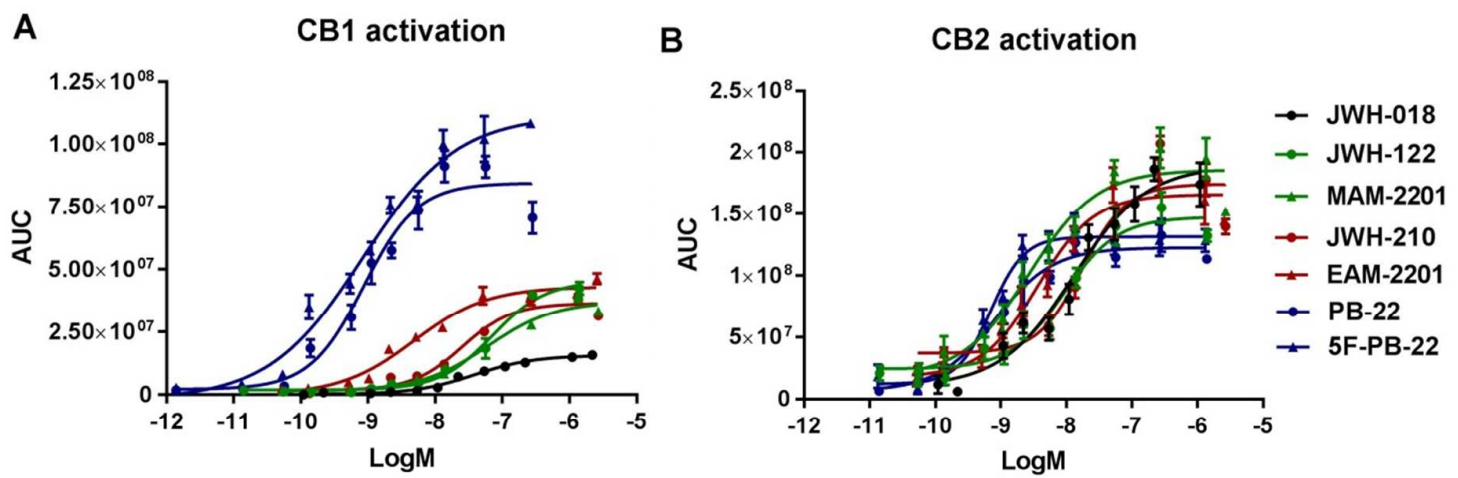

CB1 activation
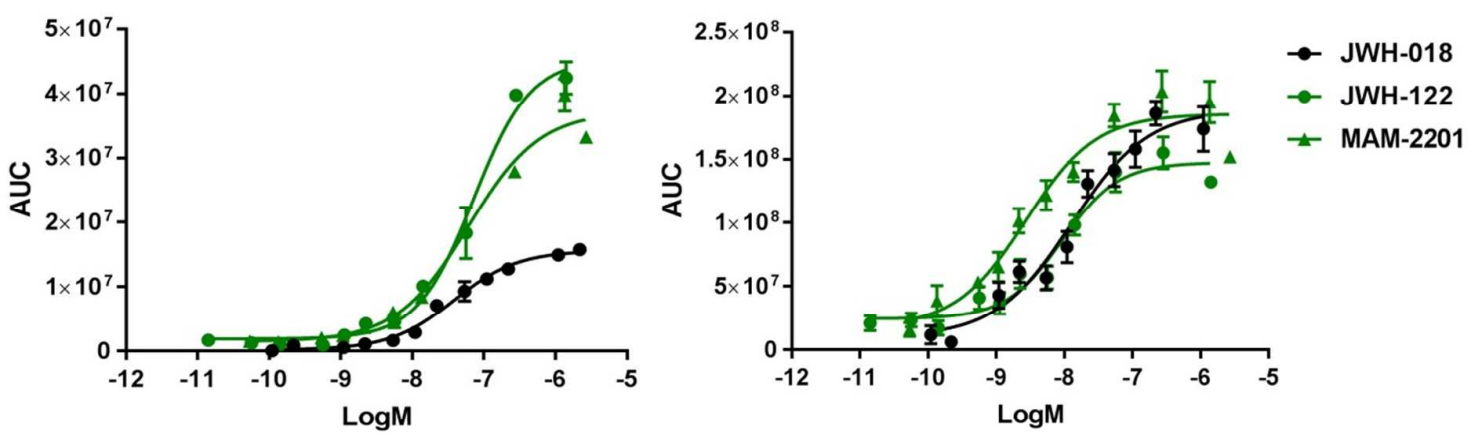

CB1 activation
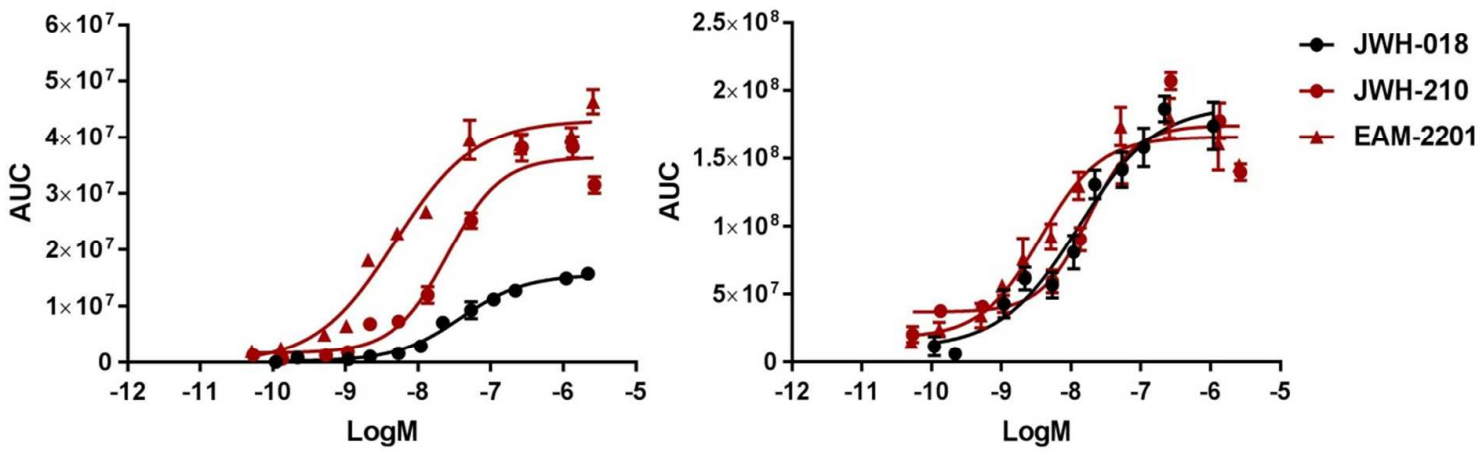

CB1 activation
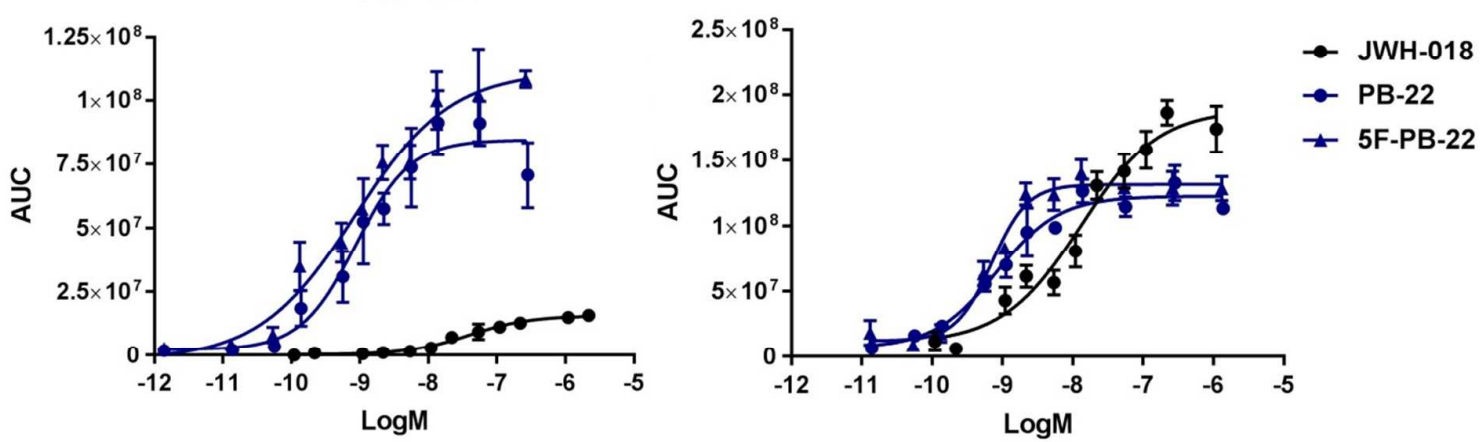

Figure S-4. The concentration-dependent interaction of CB1 (A) and CB2 (B) with ßarr2 upon stimulation with different SCs. AUC, area under the curve. Data are given as mean AUC \pm SEM $(n=5-6)$. 


\section{Supplementary Data S-5}

Table S-5 shows the potency $\left(\mathrm{EC}_{50}\right)$ of $\Delta^{9} \mathrm{THC}$ and JWH-018, determined by different functional assays.

\begin{tabular}{|c|c|c|c|c|}
\hline Drug & Functional assay & CB1 EC $50(\mathrm{nM})$ & $\mathrm{CB} 2 \mathrm{EC}_{50}(\mathrm{nM})$ & Reference \\
\hline \multirow[t]{3}{*}{$\Delta^{9} \mathrm{THC}$} & GTPyS binding & $\begin{array}{l}81 \pm 34 \\
167 \pm 84.7 \\
77.0 \pm 29.9\end{array}$ & $\begin{array}{l}- \\
- \\
-\end{array}$ & $\begin{array}{l}\text { Breivogel et al. }(2001)^{1} \\
\text { Brents et al. }(2011)^{2} \\
\text { Brents et al. }(2012)^{3}\end{array}$ \\
\hline & $\begin{array}{l}\text { FLIPR membrane } \\
\text { potential assay }\end{array}$ & $\begin{array}{l}250 \\
172\end{array}$ & $\begin{array}{l}1157 \\
-\end{array}$ & $\begin{array}{l}\text { Banister et al. }(2015 a)^{4} \\
\text { Banister et al. }(2015 b)^{5}\end{array}$ \\
\hline & $\begin{array}{l}\text { Adenylate cyclase } \\
\text { inhibition }\end{array}$ & - & $57.9 \pm 19.8$ & Rajaskaran et al. $(2013)^{6}$ \\
\hline \multirow[t]{4}{*}{ JWH-018 } & GTPYS binding & $\begin{array}{l}36 \\
6.8 \pm 2.5 \\
20.2 \pm 1.3\end{array}$ & $\begin{array}{l}- \\
- \\
-\end{array}$ & $\begin{array}{l}\text { Nakajima et al. }(2011)^{7} \\
\text { Brents et al. }(2011)^{2} \\
\text { De Luca et al. }(2013)^{8}\end{array}$ \\
\hline & $\begin{array}{l}\text { FLIPR membrane } \\
\text { potential assay }\end{array}$ & $\begin{array}{l}102 \\
18\end{array}$ & $\begin{array}{l}133 \\
22\end{array}$ & $\begin{array}{l}\text { Banister et al. }(2015 a)^{4} \\
\text { Banister et al. }(2015 b)^{5}\end{array}$ \\
\hline & $\begin{array}{l}\text { Adenylate cyclase } \\
\text { inhibition }\end{array}$ & - & $3.6 \pm 2.2$ & Rajaskaran et al. $(2013)^{6}$ \\
\hline & Internalization assay & $\begin{array}{l}2.8 \\
10.1\end{array}$ & - & $\begin{array}{l}\text { Atwood et al. }(2010)^{9} \\
\text { Atwood et al. }(2011)^{10}\end{array}$ \\
\hline
\end{tabular}

Table S-5. Potency of $\Delta^{9} \mathrm{THC}$ and JWH-018.

\section{References}

1.Breivogel, C. S.; Griffin, G.; Di Marzo, V.; Martin, B. R., Mol Pharmacol 2001, 60, 155-63.

2.Brents, L. K.; Reichard, E. E.; Zimmerman, S. M.; Moran, J. H.; Fantegrossi, W. E.; Prather, P. L., PLoS One 2011, 6.

3.Brents, L. K.; Gallus-Zawada, A.; Radominska-Pandya, A.; Vasiljevik, T.; Prisinzano, T. E.; Fantegrossi, W. E.; Moran, J. H.; Prather, P. L., Biochem Pharmacol 2012, 83, 952-61.

4.Banister, S. D.; Stuart, J.; Kevin, R. C.; Edington, A.; Longworth, M.; Wilkinson, S. M.; Beinat, C.; Buchanan, A. S.; Hibbs, D. E.; Glass, M.; Connor, M.; McGregor, I. S.; Kassiou, M., ACS Chem Neurosci 2015, 6, 1445-58.

5.Banister, S. D.; Moir, M.; Stuart, J.; Kevin, R. C.; Wood, K. E.; Longworth, M.; Wilkinson, S. M.; Beinat, C.; Buchanan, A. S.; Glass, M.; Connor, M.; McGregor, I. S.; Kassiou, M., ACS Chem Neurosci 2015, 6, 1546-59.

6.Rajasekaran, M.; Brents, L. K.; Franks, L. N.; Moran, J. H.; Prather, P. L., Toxicol Appl Pharmacol 2013, 269, $100-8$.

7.Nakajima, J., Takahashi, M., Nonaka, R., Seto, T., Suzuki, J., Yoshida, M., Kanai,C., Hamano, T., Forensic Toxicology 2011, $29,132-141$.

8.De Luca M.A., C. M. P., Loi B., Porcu A., Martorelli M., Miliano C., Kellett K., Davidson C., Stair L.J., Schifano F., Di Chiara G., Neuropharmacology 2015, 15.

9.Atwood, B. K.; Huffman, J.; Straiker, A.; Mackie, K., Br J Pharmacol 2010, 160, 585-93.

10.Atwood, B. K.; Lee, D.; Straiker, A.; Widlanski, T. S.; Mackie, K., Eur J Pharmacol 2011, 659, 139-45. 
Supplementary Data S-6

\begin{tabular}{|c|c|c|}
\hline Drug/metabolite & $\begin{array}{l}\text { Relative potential of CB1 } \\
\text { activation at } 1 \mu \mathrm{M}\end{array}$ & $\begin{array}{l}\text { Relative potential of CB2 } \\
\text { activation at } 1 \mu \mathrm{M}\end{array}$ \\
\hline JWH-018 & $100.0 \pm 10.6(20)$ & $100 \pm 17.6(20)$ \\
\hline 4-OH-pentyl JWH-018 & $90.3 \pm 10.9(4)$ & $102.3 \pm 9.5(4)$ \\
\hline 5-OH-pentyl-JWH-018 & $20.7 \pm 5.3(4)$ & $85.1 \pm 13.2(4)$ \\
\hline 5-OH-indole-JWH-018 & $73.1 \pm 18.3(3)$ & $70.8 \pm 24.0(4)$ \\
\hline 6-OH-indole-JWH-018 & $24.1 \pm 4.1(4)$ & $75.7 \pm 4.3(4)$ \\
\hline N-pentanoic acid JWH-018 & $0.53 \pm 1.77(4)$ & $15.9 \pm 12.6(4)$ \\
\hline JWH-122 & $173.4 \pm 17.6(4)$ & $94.0 \pm 7.5(4)$ \\
\hline 4-OH-pentyl-JWH-122 & $165.2 \pm 13.0(3)$ & $99.4 \pm 4.1(4)$ \\
\hline MAM-2201 & $174.7 \pm 31.2(3)$ & $97.4 \pm 23.0(3)$ \\
\hline 5-OH-pentyl-JWH-122 & $99.5 \pm 5.9(4)$ & $96.3 \pm 10.9(4)$ \\
\hline 4-OH-pentyl-MAM-2201 & $173.0 \pm 20.2(4)$ & $87.6 \pm 13.5(4)$ \\
\hline N-pentanoic acid JWH-122 & $1.4 \pm 3.7(4)$ & $3.6 \pm 6.2(3)$ \\
\hline JWH-210 & $197.9 \pm 13.3(4)$ & $84.5 \pm 12.0(4)$ \\
\hline 4-OH-pentyl-JWH-210 & $179.3 \pm 19.0(3)$ & $115.4 \pm 22.2(4)$ \\
\hline 5-OH-pentyl-JWH-210 & $157.8 \pm 12.3(4)$ & $101.4 \pm 12.7(4)$ \\
\hline 5-OH-indole-JWH-210 & $100.3 \pm 13.4(3)$ & $90.9 \pm 18.9(4)$ \\
\hline EAM-2201 & $239.7 \pm 10.5(4)$ & $92.4 \pm 25.3(4)$ \\
\hline N-pentanoic acid JWH-210 & $1.9 \pm 1.6(3)$ & $54.8 \pm 7.8(4)$ \\
\hline PB-22 & $287.0 \pm 29.6(4)$ & $137.6 \pm 13.8(3)$ \\
\hline 3-carboxyindole PB-22 & $1.3 \pm 3.6(4)$ & $1.6 \pm 4.3(3)$ \\
\hline 4-OH-pentyl PB-22 & $208.0 \pm 21.2(4)$ & $144.6 \pm 33.0(4)$ \\
\hline $5 F-P B-22$ & $278.8 \pm 9.2(3)$ & $131.9 \pm 9.3(4)$ \\
\hline 3-carboxyindole 5F-PB-22 & $3.1 \pm 5.0(4)$ & $4.6 \pm 13.1(4)$ \\
\hline 5-OH-pentyl PB-22 & $171.0 \pm 6.9(3)$ & $142.3 \pm 13.3(4)$ \\
\hline N-pentanoic acid PB-22 & $25.8 \pm 3.4(4)$ & $43.5 \pm 5.3(4)$ \\
\hline
\end{tabular}

Table S-6. Comparison of relative potential to activate CB1 and CB2 at $1 \mu \mathrm{M}$. The data are presented as the \% CB activation (relative to the receptor activation of JWH-018) \pm SEM (number of replicates). 

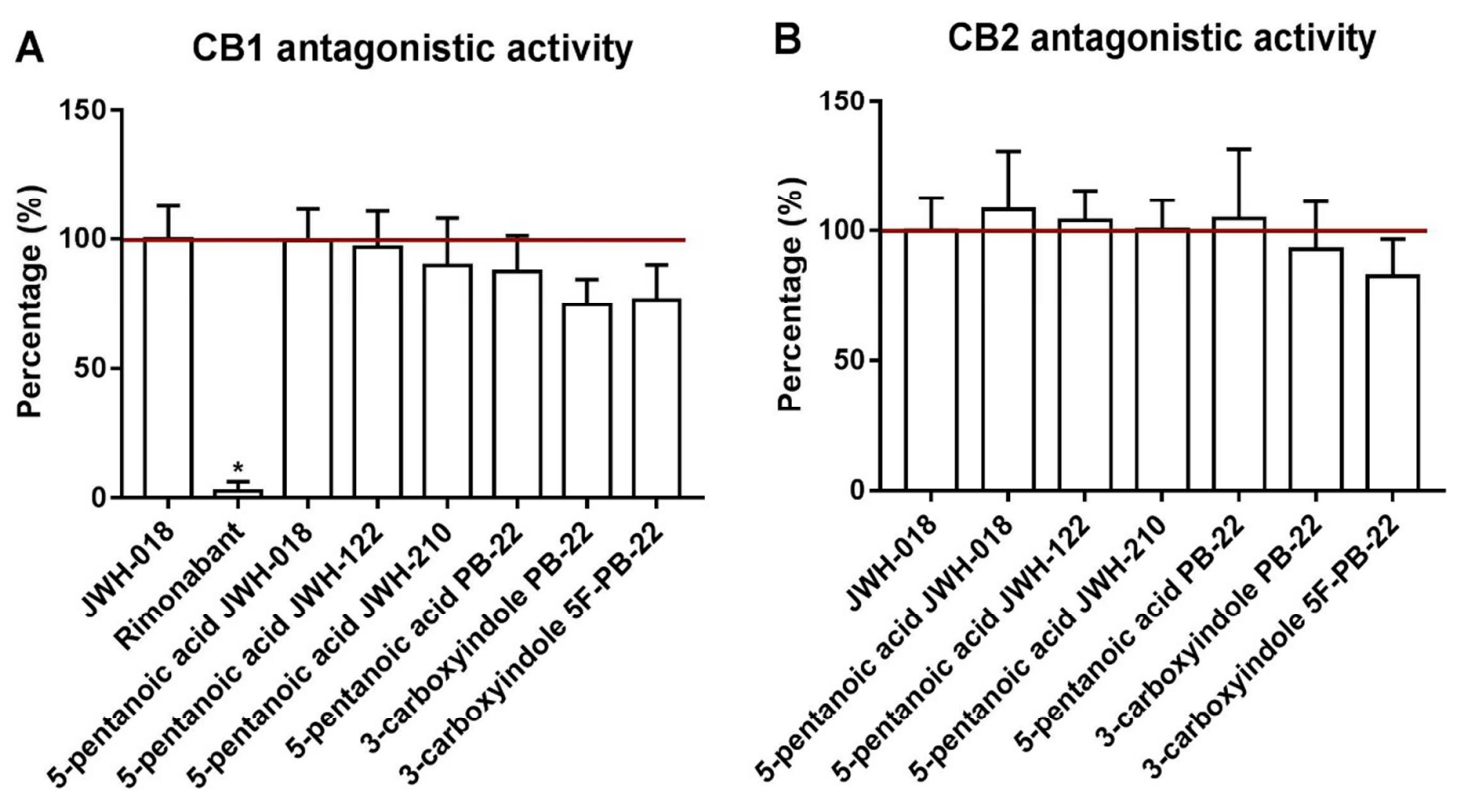

Figure S-7. Evaluation of antagonistic properties of several SC metabolites. The cells were stimulated with $1 \mu \mathrm{M}$ of the test compound and were incubated for $5 \mathrm{~min}$ before adding a fixed concentration of JWH-018 (ED80 concentration). The bar 'JWH-018' marks the response when no antagonist is present. The bar 'Rimonabant' was taken as a positive control for CB1 antagonism. Bars assigned with an $\left(^{*}\right)$ are not significantly different from basal levels. All test compounds did not show antagonistic activity. 